\title{
Tyrosine Phosphorylation Regulates the Endocytosis and Surface Expression of GluN3A-Containing NMDA Receptors
}

\author{
Dhrubajyoti Chowdhury, ${ }^{1}$ Sonia Marco, ${ }^{1}$ Ian M. Brooks, ${ }^{2}$ Aitor Zandueta, ${ }^{1}$ Yijian Rao, ${ }^{3}$ Volker Haucke, ${ }^{3}$ \\ John F. Wesseling, ${ }^{1}$ Steven J. Tavalin, ${ }^{2}$ and Isabel Pérez-Otaño ${ }^{1}$ \\ ${ }^{1}$ Cellular Neurobiology and Neurophysiology Laboratory, Center for Applied Medical Research and University of Navarra, 31008 Pamplona, Spain, \\ 2Department of Pharmacology, University of Tennessee Health Science Center, Memphis, Tennessee 38163, and ${ }^{3}$ Leibniz Institute für Molekulare \\ Pharmakologie and NeuroCure Cluster of Excellence, 13125 Berlin, Germany
}

Selective control of receptor trafficking provides a mechanism for remodeling the receptor composition of excitatory synapses, and thus supports synaptic transmission, plasticity, and development. GluN3A (formerly NR3A) is a nonconventional member of the NMDA receptor (NMDAR) subunit family, which endows NMDAR channels with low calcium permeability and reduced magnesium sensitivity compared with NMDARs comprising only GluN1 and GluN2 subunits. Because of these special properties, GluN3A subunits act as a molecular brake to limit the plasticity and maturation of excitatory synapses, pointing toward GluN3A removal as a critical step in the development of neuronal circuitry. However, the molecular signals mediating GluN3A endocytic removal remain unclear. Here we define a novel endocytic motif (YWL), which is located within the cytoplasmic C-terminal tail of GluN3A and mediates its binding to the clathrin adaptor AP2. Alanine mutations within the GluN3A endocytic motif inhibited clathrin-dependent internalization and led to accumulation of GluN3A-containing NMDARs at the cell surface, whereas mimicking phosphorylation of the tyrosine residue promoted internalization and reduced cell-surface expression as shown by immunocytochemical and electrophysiological approaches in recombinant systems and rat neurons in primary culture. We further demonstrate that the tyrosine residue is phosphorylated by Src family kinases, and that Src-activation limits surface GluN3A expression in neurons. Together, our results identify a new molecular signal for GluN3A internalization that couples the functional surface expression of GluN3A-containing receptors to the phosphorylation state of GluN3A subunits, and provides a molecular framework for the regulation of NMDAR subunit composition with implications for synaptic plasticity and neurodevelopment.

\section{Introduction}

NMDA-type glutamate receptors (NMDARs) play crucial roles in neuronal development, synaptic plasticity, and learning (Lau and Zukin, 2007). They are heterotetrameric complexes of an obligatory GluN1 subunit, at least one GluN2 (A-D), and sometimes GluN3 (A-B) subunits (Cull-Candy and Leszkiewicz, 2004), which assemble in multiple combinations to generate NMDAR subtypes that differ in biophysical, signaling, and trafficking properties. GluN1/GluN2 heteromers are characterized by a high calcium $\left(\mathrm{Ca}^{2+}\right)$ permeability and strong voltagedependent magnesium $\left(\mathrm{Mg}^{2+}\right)$ block. In contrast, incorporation of GluN3A subunits yields channels with reduced single-channel

\footnotetext{
Received June 7, 2012; revised Jan. 2, 2013; accepted Jan. 12, 2013.

Author contributions: D.C., V.H., S.J.T., and I.P.-O. designed research; D.C., SM., I.M.B., Y.R., S.J.T., and I.P.-0. performed research; A.Z., V.H., and I.P.-0. contributed unpublished reagents/analytic tools; D.C., S.M., V.H., J.F.W., S.J.T., and I.P.-0. analyzed data; D.C., J.F.W., S.J.T., and I.P.-0. wrote the paper.

Work was funded by the UTE project CIMA, Gobierno de Navarra, TCP, Brain and Behavior Fund (NARSAD): Spanish Ministry of Science Grants SAF2010-20636 and CSD2008-00005 (I.P.0.) and BFU2009-12160 (J.F.W.); by the Deutsche Forschungsgemeinschaft SFB 958/A01 and Exc 257/NeuroCure Grant (V.H.); and by the University of Tennessee Neuroscience Institute and National Institutes of Health Grants NS046661 and NS076637 (S.J.T.). We thank Rebeca Martínez-Turrillas for excellent technical help, and Edouard Saint-Michel, Mike Ehlers, and Tomás Aragón for advice at different phases of this work.

Correspondence should be addressed to Isabel Pérez-Otaño, Edificio CIMA, Avda Pio XII, 55, 31008 Pamplona Spain. E-mail: otano@unav.es.

DOI:10.1523/JNEUROSCI.2721-12.2013

Copyright $\odot 2013$ the authors $\quad 0270-6474 / 13 / 334151-14 \$ 15.00 / 0$
}

conductance and lower $\mathrm{Ca}^{2+}$ permeability and sensitivity to $\mathrm{Mg}^{2+}$ blockade, which might serve a dominant-negative role in NMDAR transmission (Perez-Otano et al., 2001; Sasaki et al., 2002). The expression and synaptic incorporation of GluN3A is highest during a narrow window of postnatal brain development when intense synapse formation and refinement take place, but downregulates sharply thereafter (Wong et al., 2002). Loss-offunction and gain-of-function studies indicate that downregulation of juvenile GluN3A-containing NMDARs and their replacement by mature subtypes is critical for the maturation of excitatory synapses (Roberts et al., 2009; Larsen et al., 2011; Henson et al., 2012).

Like most integral membrane proteins, NMDARs traffic between the plasma membrane and intracellular compartments via vesicle-mediated membrane delivery and endocytosis. Controlled endocytic removal of NMDARs from the neuronal surface is a powerful mode for regulating their abundance and subunit composition during synapse maturation (Roche et al., 2001; Barria and Malinow, 2002; Pérez-Otaño et al., 2006), long-term depression (LTD; Snyder et al., 2001), and in response to ligand binding (Vissel et al., 2001; Nong et al., 2003). To date, several endocytic motifs have been identified within cytosolic domains of GluN1, GluN2A, and GluN2B that might mediate these processes (Lavezzari et al., 2004; Scott et al., 2004). However, knowledge of the cellular mechanisms controlling GluN3A endocytosis 
is limited. A previous study implicated the multifunctional BARdomain protein syndapin 1/PACSIN 1 in the selective removal of GluN3A-containing NMDARs (Pérez-Otaño et al., 2006), but the cytoplasmic determinants of GluN3A trafficking and their precise mode of recognition by the endocytic machinery remain unknown.

Protein phosphorylation is known to regulate the exo/endocytic trafficking of glutamate receptors. For example, casein kinase 2-mediated phosphorylation of GluN2B within its PDZ binding domain disrupts its interaction with PSD-95 and drives endocytosis (Chung et al., 2004; Sanz-Clemente et al., 2010). Fyn, a member of the Src family of tyrosine kinases (SFKs), phosphorylates an endocytic motif in GluN2B and promotes surface expression by disrupting binding to the core plasma membrane adaptor AP2, which targets surface receptors into clathrin-coated pits (Prybylowski et al., 2005; Nakazawa et al., 2006). Likewise, SFK-mediated phosphorylation of a GluA2 endocytic motif regulates AMPAR endocytosis and LTD (Ahmadian et al., 2004; Hayashi and Huganir, 2004). Phosphorylation of GluN3A has not been reported.

Here, by using systematic deletion and mutations of the GluN3A C-terminal tail, combined with immunocytochemical, electrophysiological, and biochemical approaches, we identify a novel GluN3A resident tyrosine-based endocytic motif that mediates a direct interaction with AP2. We further show that SFKmediated phosphorylation of the tyrosine residue within this motif modulates GluN3A trafficking.

\section{Materials and Methods}

Antibodies, drugs, and cDNA constructs

The following primary antibodies were used for immunofluorescence: chicken anti-green fluorescent protein (GFP) (Millipore Bioscience Research Reagents), rabbit anti-GFP (Synaptic Systems), monoclonal antiTac antibody (7G7; gift from Dr. Juan Bonifacino, National Institutes of Health, Bethesda, MD), and rabbit anti- $\alpha$-adaptin (Santa Cruz Biotechnology). Fluorophore-conjugated secondary antibodies were from Jackson ImmunoResearch, unless indicated. The antibodies used for immunoblotting were as follows: rabbit anti-GluN3A (Millipore); mouse anti-GluN2B (NeuroMab); mouse anti-GFP (JL-8; Invitrogen); mouse anti- $\mu 2$ (AP50) and anti- $\alpha$-adaptin (BD Biosciences); mouse anti-AP1- $\gamma 1$, anti-MAP2c (HM-2), anti-tubulin, and anti- $\beta$-actin (Sigma); mouse anti-phosphotyrosine (4G10; Millipore); mouse antisynapsin I (Synaptic Systems); mouse anti-clathrin (TD.1; Abcam); and mouse anti-transferrin receptor (Zymed).

A stock solution of pervanadate was prepared by mixing 50 parts of 10 mM sodium orthovanadate with 1 part of $500 \mathrm{~mm}$ hydrogen peroxide. The mixture was incubated at room temperature for $10 \mathrm{~min}$. Tetrodotoxin (TTX) and D-2-amino-5-phosphonovaleric acid (APV) were obtained from Tocris Bioscience; pituitary adenylate cyclase activating peptide 38 (PACAP-38) and PP2 were from Calbiochem.

For generation of chimeric TacGluN3A constructs, fragments of the GluN3A C-terminal domain were amplified by PCR and subcloned into the cytosolic portion of Tac using XbaI and HindIII restriction sites. Mutations within the C-terminal tail were introduced by overlapping extension. The Tac pCDM8 expression vector was a gift from Dr. Pierre Cosson (Centre Médical Universitaire, Geneva, Switzerland). For bacterial expression of glutathione $S$-transferase (GST) fusion proteins, wildtype or mutant versions of the GluN3A C-terminal tail (GluN3A-Ct) were amplified by PCR and subcloned into pGEX-4T vector (GE Healthcare). GFP-tagged dominant-negative (K44A) dynamin 1 was kindly provided by Dr. Pietro De Camilli (Yale University, New Haven, CT) and Src YF and Src KD in pME18S by Dr. Tadashi Yamamoto (University of Tokyo, Japan). GST- and $\mathrm{His}_{6}$-tagged $\mu 2(158-435)$ plasmids, and GFPGluN3A, GluN1-1a, and GluN2A plasmids for mammalian expression were described previously (Pérez-Otaño et al., 2001; Kahlfeldt et al., 2010). Point mutations in GFPGluN3A were intro- duced by site-directed mutagenesis or overlapping extension, and the GFPGluN3A977 $\Delta$ truncation was generated by PCR amplification with the appropriate primers. Accuracy of the various constructs was analyzed by automated sequencing.

\section{Cell culture and transfection}

Primary cortical and hippocampal neurons were cultured from E19 rat pups as described previously (Pérez-Otaño et al., 2006). Both female and males were used. For immunocytochemistry, hippocampal neurons were plated at a density of $35,000-45,000$ per well onto $15 \mathrm{~mm}$ coverslips coated with poly-D-lysine (BD Biosciences) or with a mixture of poly-DLornithine (Sigma) and laminin (BD Biosciences), and maintained in Neurobasal medium supplemented with B27 (Invitrogen) and 5\% fetal bovine serum (FBS) (HyClone). For biochemistry, cortical neurons were plated onto $60 \mathrm{~mm}$ dishes coated with poly-D-lysine plus laminin at a density of $1 \times 10^{6}$ cells/dish. Hippocampal neurons were transfected at 9 days in vitro (DIV) with wild-type or mutant forms of GFPGluN3A using calcium phosphate for surface and internalization experiments and $\mathrm{Li}$ pofectamine 2000 (Invitrogen) for electrophysiological experiments. In both cases analysis was performed at DIV 12-14. HEK293, COS7, and HeLa cells were maintained in DMEM medium containing 10\% FBS and L-glutamine. For Tac surface and internalization assays, COS7 and HeLa cells were grown on coverslips coated with poly-D-lysine and collagen (Sigma) and transfected using Superfect (Qiagen). HEK293 cells were transfected using JetPei (Polyplus) unless indicated.

\section{Immunofluorescence}

Single cell internalization assays. COS7 cells expressing the various TacGluN3A chimeras were incubated live with anti-Tac antibody for 45 min at $4^{\circ} \mathrm{C}$ to label surface Tac, and either transferred to the $37^{\circ} \mathrm{C}$ incubator for $30 \mathrm{~min}$ to allow internalization or kept at $4^{\circ} \mathrm{C}$ (Holton et al., 2005). After fixation with $4 \%$ paraformaldehyde (PFA), $4 \%$ sucrose in PBS, cells were washed and incubated with fluorescein isothiocyanate (FITC)-conjugated secondary antibody to visualize the remaining surface Tac receptors. Cells were then permeabilized with $0.1 \%$ Triton X-100 and internalized Tac receptors were detected with a Cy3conjugated secondary antibody. After several washes, coverslips were mounted using Permafluor (ThermoFisher Scientific) and analyzed with wide-field microscopy. Cells were imaged using $25 \times$ or $40 \times$ objectives and a CoolSnap HQ camera (Roper Scientific) on a Zeiss Axiovert 200M microscope. Within individual experiments, images were acquired using fixed settings in the Cy3 (red) and FITC (green) channels for all conditions. No signal threshold was applied for assessing internalization and in all cases the experimenter was blind regarding the identity of the transfected constructs during acquisition and analysis.

Each TacGluN3A chimera was tested independently several times over multiple cultures and transfections (minimum of three experiments). For each individual experiment, we randomly imaged 40-60 transfected cells per construct and counted the number of transfected cells that contained internalized puncta. Cells were randomly chosen from two different coverslips per construct among those that were well spread and showed surface Tac staining. To avoid bias, cell selection was performed in the green channel before analysis of internalization. Internalization was scored only in cells where surface Tac receptors translocated into endocytic vesicles upon incubation at $37^{\circ} \mathrm{C}$, as confirmed by the appearance of intracellular puncta ( $>10$ puncta) that colocalized with endosomal markers (data not shown). Each experiment included as negative controls cells transfected with Tac alone, which does not show internalization at $37^{\circ} \mathrm{C}$ (see Fig. $1 \mathrm{~A}$ ), and cells transfected with the different Tac constructs but kept at $4^{\circ} \mathrm{C}$ to arrest trafficking.

A similar protocol with some modifications was used to analyze internalization of GFP-tagged GluN3A in cultured hippocampal neurons. Surface receptors were labeled with rabbit anti-GFP antibody (1:1000) for $15-20 \mathrm{~min}$ at $8^{\circ} \mathrm{C}$. Cells were then either incubated at $37^{\circ} \mathrm{C}$ for $15 \mathrm{~min}$ to allow internalization or kept at $4^{\circ} \mathrm{C}$ as a negative control. After fixation, Cy3-conjugated anti-rabbit secondary antibody was used to detect the remaining surface receptors. Internalized receptors were detected with Cy5-conjugated anti-rabbit secondary antibody following permeabilization with $0.2 \%$ Triton X-100 in PBS. Images were acquired with a 
$40 \times$ objective using the same microscopic settings for all conditions, and analyzed with the MetaMorph Imaging System (Universal Imaging). Briefly, 3-4 dendritic segments were traced per neuron, and the average intensities of surface and internalized fluorescence measured. For background correction, fluorescence intensities of equivalent areas drawn outside the labeled neurons were subtracted in each channel. Internalized to surface ratios were calculated for individual segments, data were averaged per neuron, and means from several neurons were then averaged to obtain a final mean.

Surface expression. For analysis of surface levels of TacGluN3A constructs, transfected COS7 cells plated on 12-well plates were fixed and labeled with anti-Tac antibody followed by $\mathrm{Cy} 3$-secondary antibody with (total Tac) or without permeabilization (surface Tac) in separate wells. Surface and total immunofluorescence were visualized using a Typhoon scanner, quantified with ImageJ software, and the ratio of surface to total anti-Tac signal calculated for each construct. Four individual wells were analyzed for each independent experiment, with 3-4 independent experiments performed for each construct.

Surface levels of GFPGluN3A in hippocampal neurons were measured as described previously (Pérez-Otaño et al., 2006). Briefly, neurons were live labeled with chicken anti-GFP antibody $(1: 1000)$ for $30 \mathrm{~min}$ at $37^{\circ} \mathrm{C}$, fixed with $4 \%$ PFA in PBS, washed, blocked with $4 \%$ normal serum in PBS, and incubated with Cy3-conjugated anti-chicken secondary antibody without permeabilization. Fluorescence images were acquired using a $25 \times$ objective using the same microscopic settings, and analyzed with MetaMorph. Each fluorescent neuron was traced along its entire length and the average intensities of surface fluorescence staining (red) and total GFP fluorescence (green) were calculated and background corrected. For calculations of dendritic surface levels, 4-5 individual dendritic segments were traced. For each individual neuron or dendritic segment, the average intensity of surface fluorescence staining was normalized to total GFP fluorescence to control for variations in GFPGluN3A protein expression level. Cells with either very low or very high total GFP fluorescence were excluded from the analysis to avoid artifacts from background signal or recombinant protein overload. The surface-to-total ratios from several neurons across 3-5 independent experiments performed in different cultures were pooled to obtain a mean for each condition.

siRNA knockdown and transferrin uptake. HeLa cells were transfected with siRNA duplexes using Oligofectamine (Invitrogen) following manufacturer's protocol. siRNAs against $\mu 2$-adaptin were a gift from Dr. Alberto Fraile-Ramos (University College London, London). The RNA sequences were as follows: sense, 5'GAUCAAGCGCAUGGCAGGCAUdTdT; antisense, 5'AUGCCUGCCAUGCGCUUGAUCdTdT (Fraile-Ramos et al., 2003). To evaluate AP2-silencing, transfected cells were lysed $72 \mathrm{~h}$ after siRNA transfection and lysates analyzed by immunoblot using mouse anti- $\mu 2$ adaptin. For internalization assays, cells were plated on coverslips and transfected with TacGluN3A $24 \mathrm{~h}$ after siRNA transfection. After $48 \mathrm{~h}$, transferrin (Tf) uptake and Tacinternalization were measured simultaneously. Briefly, surface Tac receptors were live labeled with mouse anti-Tac antibody after $30 \mathrm{~min}$ serum starvation. Tac internalization was allowed for $11 \mathrm{~min}$ at $37^{\circ} \mathrm{C}$ before incubation with Alexa 568-Tf $(50 \mu \mathrm{g} / \mathrm{ml})$ (Invitrogen) for 4 additional minutes. Cells were incubated with unlabeled Holo-Transferrin $(500 \mu \mathrm{g} / \mathrm{ml})$ in complete growth media for $30 \mathrm{~min}$ at $4^{\circ} \mathrm{C}$ to exchange the surface-bound Alexa 568-Tf and selectively monitor the internalized fraction of Alexa 568-Tf. Following fixation, the remaining surface Tac receptors were detected with Alexa 647-conjugated secondary antibody (Invitrogen), and internalized Tac receptors with FITC-conjugated secondary antibody before and after permeabilization, respectively. In a few coverslips, AP2 immunostaining was performed along with Tf uptake. Following fixation and permeabilization, cells were incubated with rabbit anti- $\alpha$-adaptin antibody $(1: 1000)$, followed by FITC-conjugated secondary antibody. Cells were imaged and analyzed as above.

\section{Electrophysiology}

HEK293 cells were grown on glass coverslips, transfected by calcium phosphate precipitation method with GluN1-1a, GluN2A \pm GFPGluN3A (or GFPGluN3A mutants) in a 1:1:3 ratio, and recorded from as previously described (Pérez-Otaño et al., 2006). GFP was used as a transfection marker in cells where GluN3A constructs were omitted. APV $(250 \mu \mathrm{M})$ was added to the culture medium to prevent excitotoxicity. Twenty-four hours after transfection, cells were visually selected for recording by GFP epifluorescence. Whole-cell recordings were made with either an Axopatch 200A or Multiclamp 700A amplifier (Molecular Devices). Patch pipettes ( 2 to $4 \mathrm{M} \Omega$ ) contained the following (in $\mathrm{mm}$ ): 140 Cs methanesulfonate, 10 HEPES, 5 adenosine triphosphate (Na salt), $5 \mathrm{MgCl}_{2}, 0.2$ $\mathrm{CaCl}_{2}$, and 10 BAPTA, $\mathrm{pH}$ 7.4. The extracellular solution contained the following (in mM): $150 \mathrm{NaCl}, 5 \mathrm{KCl}, 2$ or $10 \mathrm{CaCl}_{2}, 10 \mathrm{HEPES}, 10$ glucose, $\mathrm{pH} 7.4$, and was adjusted to $330 \mathrm{mOsm}$ with sucrose. Solution exchanges were accomplished through a series of flow pipes controlled by solenoid valves and moved into position by a piezoelectric bimorph. Currents were digitized at $2 \mathrm{kHz}$ and filtered at $0.5-1 \mathrm{kHz}$. Series resistance $(90-$ 95\%) and whole-cell capacitance compensation were used. Experiments were performed at a holding potential of $-80 \mathrm{mV}$ at $20^{\circ} \mathrm{C}$. A $300 \mathrm{~ms}$ voltage ramp $(-80-50 \mathrm{mV})$ protocol was elicited following a $3 \mathrm{~s}$ application of glutamate $(1 \mathrm{mM})$ and glycine $(100 \mu \mathrm{M})$ to obtain steady-state $\mathrm{I}-\mathrm{V}$ relationships. Membrane currents elicited by the ramp protocol in the absence of agonists were subtracted from the glutamate-gated ramp currents to generate the net I-V relationship. The shift in reversal potential $\left(\Delta E_{\text {rev }}\right)$, reflecting the relative calcium permeability of functional NMDARs, was calculated by subtracting the $E_{\mathrm{rev}}$ obtained in $2 \mathrm{mM} \mathrm{Ca}^{2+}$ from the $E_{\text {rev }}$ measured in $10 \mathrm{mM} \mathrm{Ca}^{2+}$ and corrected for the junction potential between solutions. Currents were monitored when switching extracellular $\mathrm{Ca}^{2+}$ by evoking a $1 \mathrm{~s}$ application of agonists every $30 \mathrm{~s}$ until the current level reached a stable value indicating that exchange of extracellular $\mathrm{Ca}^{2+}$ was complete. The peak amplitude from these $1 \mathrm{~s}$ agonist applications in $2 \mathrm{~mm} \mathrm{Ca}^{2+}$ was used to calculate the current density. Desensitization was quantified as the ratio of current remaining at the end of the $1 \mathrm{~s}$ agonist application to the peak current.

Hippocampal neurons were recorded in the whole-cell configuration as described above using capacitance and series resistance compensation (70-85\%). The extracellular bath solution contained the following (in mM): $150 \mathrm{NaCl}, 5 \mathrm{KCl}, 2 \mathrm{CaCl}_{2}, 0.1 \mathrm{MgCl}_{2}, 10$ HEPES, 10 glucose, $\mathrm{pH} 7.4$, and was supplemented with $10 \mu \mathrm{M}$ glycine, $500 \mathrm{~nm}$ TTX, $100 \mu \mathrm{M}$ picrotoxin, and $10 \mu \mathrm{M}$ NBQX. Cells' membrane potential was held at $-60 \mathrm{mV}$ or $+40 \mathrm{mV}$ and current responses were evoked by $5 \mathrm{~s}$ applications of NMDA $(100 \mu \mathrm{M})$.

\section{GST fusion protein purification and pull-down assays}

Cultures from bacteria transformed with the different GST fusion constructs (Escherichia coli BL21 strain) were grown at $30^{\circ} \mathrm{C}$ until $\mathrm{OD}_{600 \mathrm{~nm}}=0.4-0.7$, and isopropyl $\beta$-D-1-thiogalactopyranoside (Sigma; $0.1 \mathrm{~mm}$ ) was added for 2-3 $\mathrm{h}$ to induce protein expression. Cultures were harvested, lysed in cold lysis buffer (PBS, 1.5\% Sarkosyl, $5 \mathrm{~mm}$ dithiothreitol, $1 \mathrm{mg} / \mathrm{ml} \mathrm{ly-}$ sozyme, $0.1 \mathrm{~mm}$ PMSF, protease inhibitors; Complete, Roche), and nutated for $15 \mathrm{~min}$ at $4^{\circ} \mathrm{C}$. The samples were sonicated and centrifuged at $3000 \times g$ for $10 \mathrm{~min}$ at $4^{\circ} \mathrm{C}$. The supernatants were adjusted to $2 \%$ Triton X-100 and incubated with one-tenth volume of a 50\% glutathioneagarose beads slurry (Sigma) overnight at $4^{\circ} \mathrm{C}$. Beads were washed three times with PBS, and the purity of agarose-adsorbed GST fusion proteins was assessed by SDS-PAGE followed by Coomassie blue staining.

For GST-GluN3A-Ct pull-downs, mouse forebrain cytosolic fractions were obtained through subcellular fractionation. Briefly, brains were removed following decapitation, and the forebrain was dissected and homogenized in 10 volumes of homogenization buffer ( $0.32 \mathrm{M}$ sucrose, 4 mм HEPES, pH 7.4, 1 mм EDTA, 1 mм EGTA, 0.1 mм PMSF, protease inhibitors) by 10-15 strokes in a motor-driven glass-Teflon homogenizer. Homogenates were spun at $1000 \times g$ for $10 \mathrm{~min}$ to remove the nuclear fraction, and supernatants were centrifuged at $200,000 \times g$ for 30 min to obtain crude membrane fraction (pellet) and soluble cytosolic fraction. Protein concentrations were measured using BCA assay (ThermoFisher Scientific), and 100-200 $\mu \mathrm{g}$ of cytosolic fractions were precleared with GST-agarose beads in $800 \mu \mathrm{l}$ of binding buffer $(10 \mathrm{~mm}$ HEPES, pH 7.4, $150 \mathrm{~mm} \mathrm{NaCl}, 0.5 \%$ Triton X-100, 0.1 mм PMSF, protease inhibitors) for $1 \mathrm{~h}$ at $4^{\circ} \mathrm{C}$. After centrifugation at $1000 \times g$ for $5 \mathrm{~min}$, precleared cytosolic fractions were incubated with equivalent amounts of different GST fusion proteins conjugated to agarose beads for $90 \mathrm{~min}$ at 
$4^{\circ} \mathrm{C}$. GST alone was used as a negative control to rule out nonspecific binding to the GST tag. Beads were washed three times with binding buffer with $0.1 \%$ Triton X-100 and once with same buffer without $\mathrm{NaCl}$. The final pellets were resuspended in SDS sample buffer and boiled for 5 min to elute the bound proteins. Eluates were subjected to SDS-PAGE, proteins were transferred onto PVDF membranes (GE Healthcare), and detected by immunoblotting. GST fusion proteins were visualized by Ponceau S (Sigma) staining of the PVDF membrane. Immunoblotting was performed with various primary antibodies, and horseradish peroxidase-conjugated secondary antibodies (GE Healthcare) were applied before ECL detection (GE Healthcare). Films were scanned and nonsaturating, immunoreactive bands were quantitated using ImageQuant 5.2 (Molecular Dynamics) software. The amount of bound protein was quantified by normalizing the corresponding immunoreactive band with the Ponceau-stained band within each lane. For sequential reprobing of the same blots, the membranes were stripped and subjected to immunoblotting with another antibody.

For GST- $\mu 2$ pull-downs, whole-cell lysates from HEK293 cells expressing wild-type or mutant GluN3A were used. Twenty-four hours post-transfection, cells were collected in PBS, resuspended in lysis buffer (50 mM HEPES, 1\% Triton X-100, 0.1 mM PMSF, protease inhibitors), and nutated for $1 \mathrm{~h}$ at $4^{\circ} \mathrm{C}$. Insoluble material was cleared by centrifuging at $14,000 \times g$ for $30 \mathrm{~min}$ and $50-80 \mu \mathrm{g}$ of the resulting cell lysates used for pull-down as described above. Phosphatase inhibitors (10 mM sodium pyrophosphate, $1 \mathrm{~mm}$ sodium orthovanadate, $10 \mathrm{~mm}$ sodium fluoride) were included in the buffers. Bound proteins were analyzed by immunoblotting.

\section{Direct binding assay}

His $_{6}$-tagged $\mu 2$ (amino acids 158-435) was expressed and purified using HIS-Select nickel affinity gel (Sigma) following the manufacturer's instructions. The proteins were further purified by size exclusion chromatography (Superdex S200; GE Healthcare) in 20 mm HEPES, pH 7.4, containing $200 \mathrm{~mm} \mathrm{NaCl}$. GST fusion proteins $(7 \mu \mathrm{g})$ were incubated with $7 \mu \mathrm{g}$ of $\mathrm{His}_{6}-\mu 2$ for $1 \mathrm{~h}$ at $4^{\circ} \mathrm{C}$ in $100 \mu$ of pull-down buffer $(20 \mathrm{~mm}$ Tris- $\mathrm{HCl}, \mathrm{pH} 7.4,150 \mathrm{~mm} \mathrm{NaCl}, 5 \mathrm{~mm}$ imidazole, $2 \mathrm{~mm} \mathrm{MgCl}_{2}, 1 \%$ Triton X-100). Beads were washed, resolved by SDS-PAGE, and analyzed by Coomassie staining.

\section{Immunoprecipitation}

For coimmunoprecipitation of native GluN3A and AP2 (see Figs. 5D, $7 C$ ), crude membrane extracts from mouse forebrain or cultured cortical neurons were solubilized in lysis buffer $(50 \mathrm{~mm}$ Tris, $\mathrm{pH} 9,1 \%$ deoxycholate) at $36^{\circ} \mathrm{C}$ for $30 \mathrm{~min}$. Insoluble material was cleared by centrifuging at $100,000 \times g$ for $30 \mathrm{~min}$, and the resulting supernatants dialyzed overnight against binding buffer $(50 \mathrm{~mm}$ Tris, $\mathrm{pH} 7.4,0.1 \%$ Triton $\mathrm{X}-100)$ to avoid interference of the detergent during immunoprecipitation. Lysate $(150-300 \mu \mathrm{g})$ was precleared with protein G-agarose beads (ThermoFisher Scientific) for $30 \mathrm{~min}$ at $4^{\circ} \mathrm{C}$. Precleared extracts were incubated with $5 \mu \mathrm{g}$ of rabbit anti- $\alpha$-adaptin (Santa Cruz Biotechnology), rabbit anti-GluN3A (Millipore), or control IgG for $3 \mathrm{~h}$ at $4^{\circ} \mathrm{C}$ followed by $2 \mathrm{~h}$ incubation with protein $\mathrm{G}$-agarose beads. Beads were washed four times with binding buffer, and immunoprecipitated proteins eluted with SDS sample buffer for subsequent electrophoresis and immunoblotting.

For phosphotyrosine immunoprecipitation (see Fig. 6C), crude membrane extracts from mouse forebrain were solubilized in $10 \mathrm{~mm}$ Tris, $\mathrm{pH}$ 7.4, $1 \mathrm{~mm}$ EDTA, $1 \mathrm{~mm} \mathrm{EGTA,} \mathrm{and} 2 \% \mathrm{SDS}$ at $95^{\circ} \mathrm{C}$ for $5 \mathrm{~min}$. Insoluble material was cleared by centrifuging at $100,000 \times g$. The supernatants were diluted with ice-cold immunoprecipitation buffer ( $10 \mathrm{~mm}$ sodium phosphate dibasic, pH 7.2, 1\% Triton X-100, $150 \mathrm{~mm} \mathrm{NaCl}, 1 \%$ sodium deoxycholate, $2 \mathrm{~mm}$ EDTA) and immunoprecipitation was performed as described above, except using $10 \mu \mathrm{g}$ mouse anti-phosphotyrosine antibody (4G10) (Millipore).

For GFPGluN3A immunoprecipitation (Fig. 6A,B), whole-cell lysates from HEK293 cells expressing the indicated cDNA constructs were prepared as described before. Lysates $(100 \mu \mathrm{g})$ were resuspended in immunoprecipitation buffer (10 mM sodium phosphate dibasic, $\mathrm{pH} 7.2,1 \%$ Nonidet P-40, $150 \mathrm{~mm} \mathrm{NaCl}, 1 \%$ sodium deoxycholate, $0.1 \%$ SDS, $2 \mathrm{~mm}$
EDTA) and immunoprecipitated as above but using $3 \mu \mathrm{g}$ of anti-GFP antibody (Synaptic Systems). All buffers contained $1 \mathrm{~mm}$ orthovanadate and protease inhibitors.

\section{Cell surface biotinylation}

HEK293 cells transfected with wild-type or mutant GluN3A along with GluN1 (1:1 ratio) were washed with PBS+ (PBS, $1 \mathrm{~mm} \mathrm{MgCl}_{2}, 0.1 \mathrm{~mm}$ $\mathrm{CaCl}_{2}$ ) and incubated with the membrane-impermeant reagent EZ-Link sulfo-NHS-SS-biotin $(1 \mathrm{mg} / \mathrm{ml})$ (ThermoFisher Scientific) in PBS+ for $15 \mathrm{~min}$ at $4^{\circ} \mathrm{C}$. Unreacted free biotin was quenched by incubation with 50 $\mathrm{mm}$ glycine in PBS + for $10 \mathrm{~min}$ at $4^{\circ} \mathrm{C}$. Cells were then washed with cold PBS +, harvested by scraping into collection buffer (PBS, $0.1 \mathrm{mM} \mathrm{CaCl}_{2}$, $1 \mathrm{~mm}$ orthovanadate, protease inhibitors), and pelleted by centrifugation at $1000 \times g$ for $10 \mathrm{~min}$. Cell pellets were solubilized in lysis buffer $(10 \mathrm{~mm}$ PB, pH 7.4, 150 mм NaCl, 5 mм EDTA, 0.1\% SDS, 1\% Triton X-100, 1 $\mathrm{mm}$ orthovanadate, protease inhibitors) for $30 \mathrm{~min}$ and insoluble material cleared by centrifugation at $16,000 \times g$ for $30 \mathrm{~min}$. Biotinylated proteins were recovered by incubating lysates with UltraLink NeutrAvidin Plus beads (ThermoFisher Scientific) for $2 \mathrm{~h}$ at $4^{\circ} \mathrm{C}$. Beads were washed four times with lysis buffer without SDS, and bound surface proteins eluted in SDS sample buffer by boiling. Surface fractions eluted from beads and corresponding total lysates for each sample were run in parallel and analyzed by quantitative immunoblotting as described. Surface expression was calculated by dividing the amount of protein in surface fractions by that in total lysate and expressed as surface-to-total ratio. In addition, blots were probed for intracellular proteins, such as tubulin, to exclude nonspecific uptake of free biotin.

For biotinylation assays in high-density cultured cortical neurons, DIV 10 neurons were incubated in prewarmed artificial CSF ( $\mathrm{aCSF}), \mathrm{pH}$ 7.3, containing the following (in mM): 10 HEPES, $150 \mathrm{NaCl}, 3 \mathrm{KCl}, 10$ glucose, $2 \mathrm{CaCl}_{2}$, and $1 \mathrm{MgCl}_{2}$ for $30 \mathrm{~min}$. Cells were treated with relevant agents in aCSF, followed by wash with aCSF alone. Cells were processed for biotinylation as described above except that aCSF was used in place of PBS+.

\section{In vitro phosphorylation of GluN3A-Ct fusion proteins}

GST fusion proteins of the GluN3A-Ct with either Y971 alone or all three tyrosine residues mutated to phenylalanines were generated as above. In vitro phosphorylation was performed by incubating GST-proteins with 9 units of recombinant human c-Src (Millipore Biotechnology) and $5 \mu \mathrm{Ci}$ of $\left[\gamma_{-}{ }^{32} \mathrm{P}\right] \mathrm{ATP}$ (PerkinElmer) for $1 \mathrm{~h}$ at $37^{\circ} \mathrm{C}$ in $30 \mu \mathrm{l}$ of phosphorylation buffer (50 mu Tris- $\mathrm{HCl}, \mathrm{pH} 7.4,3 \mathrm{~mm} \mathrm{MnCl}_{2}, 10 \mathrm{~mm} \mathrm{MgCl}_{2}$ ) including $83.33 \mu \mathrm{M}$ unlabeled ATP (Sigma). No fusion protein was included in control reactions. The reactions were stopped by boiling in SDS sample buffer. The samples were resolved by SDS-PAGE, the gel was stained by Coomassie blue (Bio-Rad), and dried and subjected to autoradiography. The radioactive signal and Coomassie staining for each GST fusion protein were quantitated with ImageQuant 5.2. Radioactive incorporation was normalized by the value of the Coomassie-stained band.

\section{Results}

The C-terminal domain of GluN3A carries an autonomous endocytic signal

We first evaluated whether GluN3A-containing receptors undergo internalization in HEK293 cells coexpressing an N-terminal GFP-tagged GluN3A (GFPGluN3A; Fig. 1A, top left) along with GluN1 and GluN2A using antibody uptake-based assays. Surface receptors were live labeled with anti-GFP antibody at $4^{\circ} \mathrm{C}$ and then incubated at $37^{\circ} \mathrm{C}$ for $30 \mathrm{~min}$ to allow endocytosis. We found that surface GluN3A-containing receptors redistributed to punctate vesicular structures corresponding to internalized receptors (Fig. 1A, left). The internalized GluN3A thus measured represents heteromeric GluN3A complexes, as GluN3A by itself cannot reach the plasma membrane (PérezOtaño et al., 2001).

Because internalization could be mediated by endocytic motifs within GluN1, GluN2, or GluN3A subunits, we created a chimera by appending the cytoplasmic $\mathrm{C}$ terminus of rat GluN3A 
A
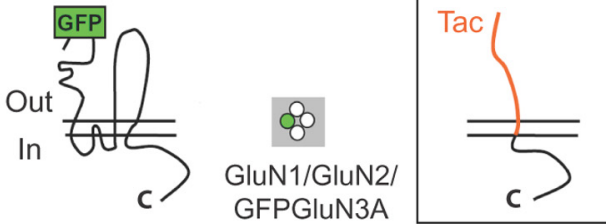

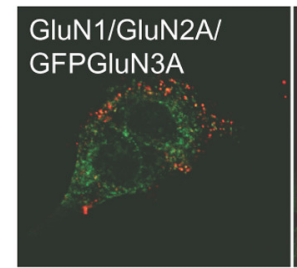

Total Int 30 min

C
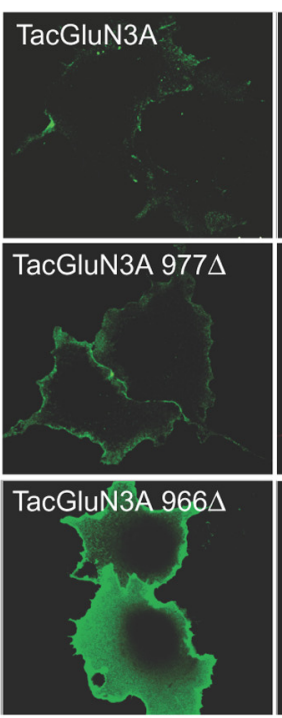

Surface

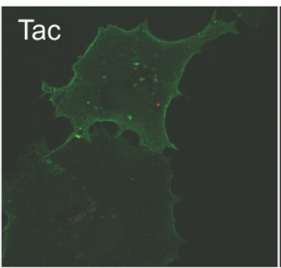

Surface Int 30 min
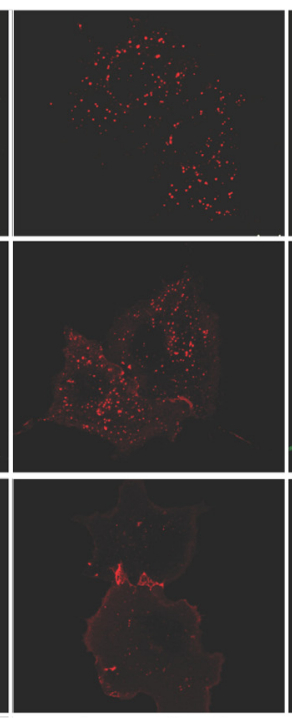

Internalized

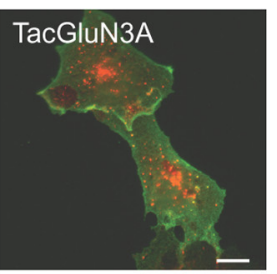

Surface Int 30 min

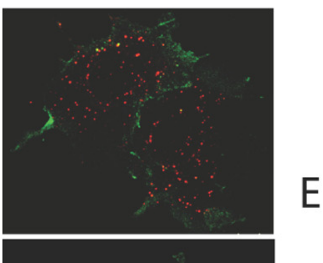

B
$952 \quad 1115$

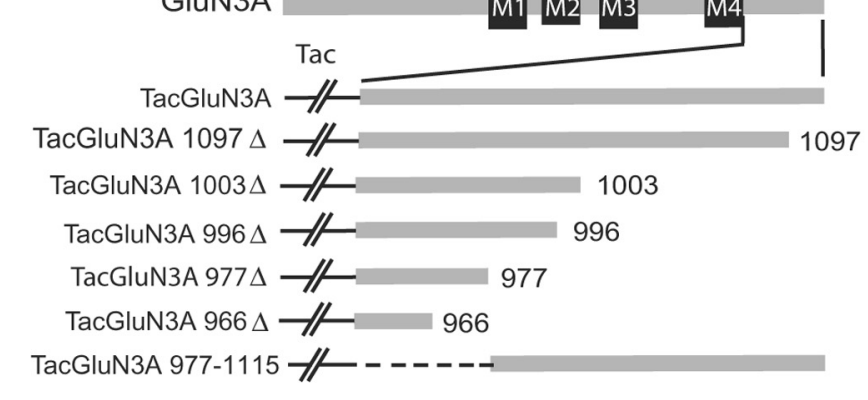

\section{D}
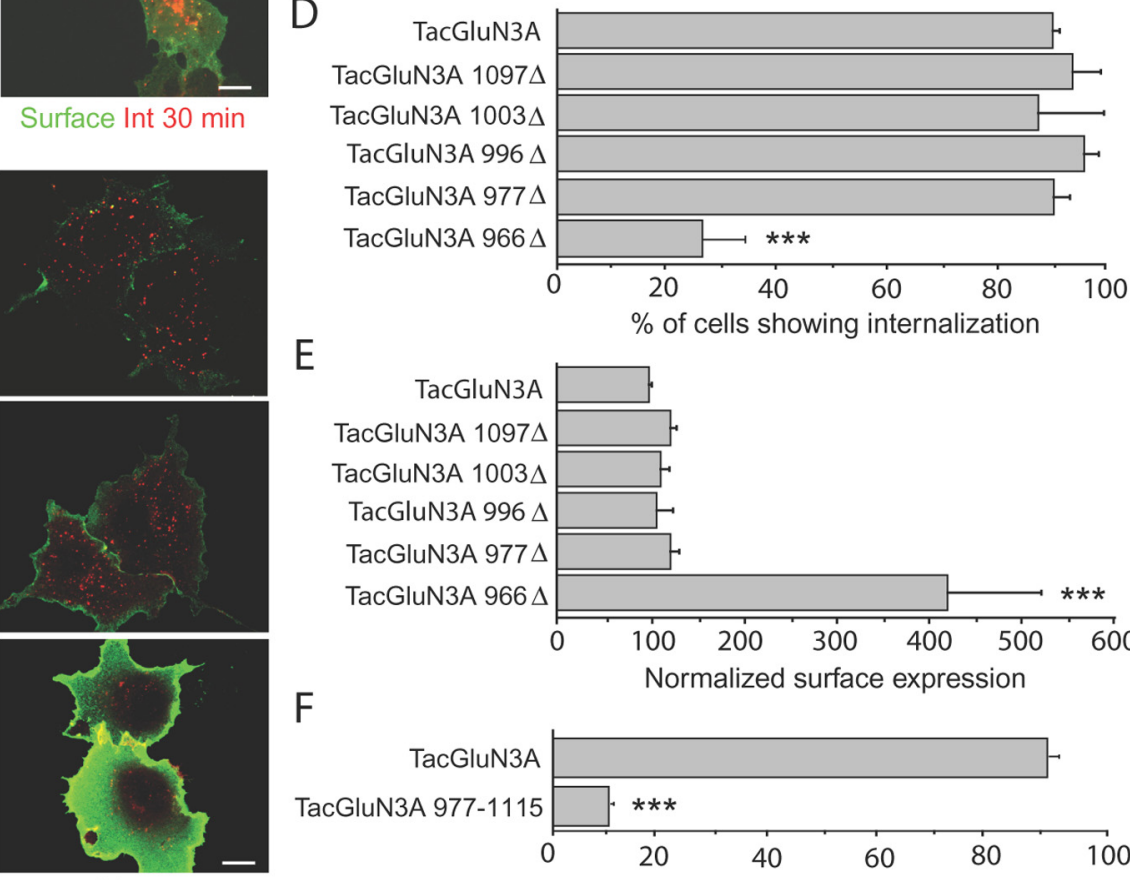

Merge
TacGluN3A

TacGlun3A 1097A

TacGluN3A $1003 \Delta$

TacGluN3A $996 \Delta$

TacGluN3A $977 \Delta$

TacGluN3A $966 \Delta$

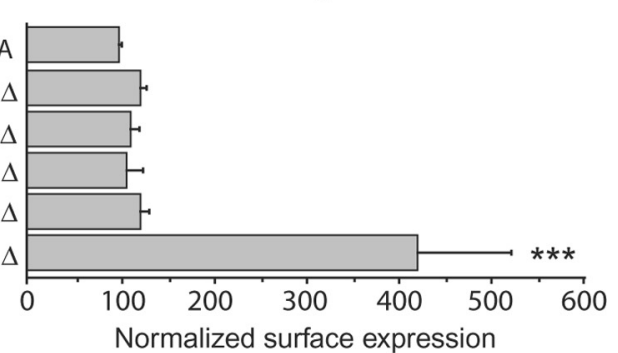

$\mathrm{F}$

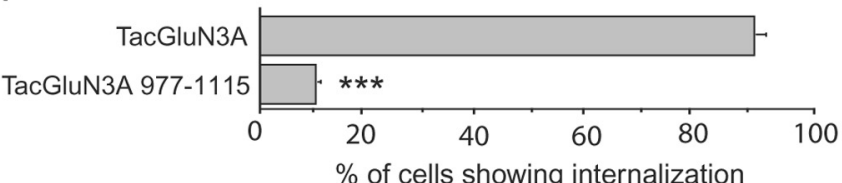

Figure 1. The GluN3AC terminus contains an autonomous endocytic signal. $A$, Either full-length GluN3A carrying an extracellular GFP-tag along with GluN1 and GluN2A, or the GluN3AC terminus alone fused to the interleukin-2 $\alpha$ receptor (Tac), was transfected into HEK293 or COS7 cells, respectively. Cells were incubated live with anti-GFP or anti-Tac antibody at $4^{\circ} \mathrm{C}$, washed, and returned to $37^{\circ} \mathrm{C}$ for $30 \mathrm{~min}$ to allow endocytosis. After fixation and permeabilization, internalized receptors (Int; red) were visualized with Cy3-conjugated secondary antibodies. Representative images are shown; the green fluorescence arises either from total GFPGluN3A (left) or labeling of surface-expressed Tac constructs with FITC-conjugated secondary antibody before permeabilization (middle, right). Green and red channels were overlaid in all images. $\boldsymbol{B}$, Schematic representation of TacGluN3A and serial truncations of the C-terminal tail used. The C-terminal tail follows the fourth membrane domain (M4); numbers refer to the amino acid residue at which truncations were made to generate the chimeric Tac receptors. C, GluN3A C-terminal residues $952-977$ are sufficient to drive Tac endocytosis, but deleting the 966-977 stretch largely diminished internalization. Representative images are shown. Note the marked surface accumulation displayed by the internalization-defective TacGluN3A966 $\Delta$ truncation. D, Quantification of the percentage of cells showing internalization $(n=180-360$ cells analyzed from 3 to 5 independent experiments, ${ }^{* * *} p<0.001$ vs TacGluN3A, ANOVA followed by Tukey's test). Internalization was scored in cases where Tac surface staining was lost with a parallel appearance of intracellular puncta. In this and all subsequent figures, data represent mean \pm SEM. E, Surface expression of the different Tac-chimeras normalized to total expression and expressed as percentage of TacGluN3A. Note that the levels of surface expression reflected the degree of internalization for each truncation $\left(n=3-4\right.$ independent experiments, ${ }^{* * *} p<0.001$ vs TacGluN3A, ANOVA followed by Tukey's test). $\boldsymbol{F}$, A TacGluN3A construct lacking the membrane-proximal domain of GluN3A C terminus (952-976) was defective in internalization $\left(n=60-100\right.$ cells from 3 independent experiments, ${ }^{* * *} p<0.001$ vs TacGluN3A, ANOVA followed by Tukey's test). Scale bars, $20 \mu \mathrm{m}$.

(amino acids 952-1115) to the monomeric protein Tac, which consists of the extracellular and first transmembrane domain of the interleukin- $2 \alpha$ receptor (TacGluN3A; Fig. $1 A$, top right). Tac is normally stable on the plasma membrane and, as such, has been widely used to map trafficking signals within isolated protein domains. Internalization assays were performed in transfected COS7 cells using an anti-Tac antibody to label surface and internalized receptors before and after permeabilization, respectively. Both Tac and TacGluN3A were detected on the cell surface. However, whereas Tac alone did not undergo detectable endocytosis after $30 \mathrm{~min}$ at $37^{\circ} \mathrm{C}$, TacGluN3A was robustly internalized into punctate intracellular vesicles corresponding to endosomes (Fig. $1 A$, middle, right; data not shown), suggesting that the GluN3A C terminus contains a sequence that is sufficient to drive endocytosis in the absence of other NMDAR subunits.

To narrow down the region containing the putative endocytic signal, we generated serial truncations of TacGluN3A and assessed their endocytic abilities (Fig. 1B). Eliminating residues 978-1115 (TacGluN3A977A) did not alter internalization or affect steady-state surface levels compared with TacGluN3A (Fig. $1 C-E)$. Consistently, a chimera consisting solely of these amino acid residues (TacGluN3A 977-1115) did not internalize (Fig. 1F; $p<0.001$ relative to TacGluN3A). These results demonstrate that the 952-977 aa stretch next to the fourth transmembrane domain is necessary and sufficient to drive TacGluN3A endocytosis. Further deleting amino acids 967-977 caused a major reduction in 
TacGluN3A internalization $(23 \%$ of TacGluN3A966 $\Delta$-expressing cells showed internalization vs $90 \%$ for TacGluN3A, $p<0.001$; Fig. $1 C, D)$ and drove its accumulation in the cell surface $(\sim 400 \%$ relative to TacGluN3A; Fig. $1 E$ ), demonstrating a major contribution of this subdomain.

To define the sequence determinants for endocytosis within the 966-977 subdomain (Fig. 2A, shaded), we mutated triplets of residues to alanines in the TacGluN3A977 $\Delta$ chimera and assessed internalization of the mutants. Mutation of the YWL subset of residues dramatically inhibited GluN3A endocytosis (23\% of TacGluN3A977 $\quad$ (YWL/AAA)-expressing cells showed internalization vs $90 \%$ for TacGluN3A977 $\Delta, p<0.001$; Fig. $2 B, C)$. Internalization was not significantly affected in any of the other triple mutants, albeit the TacGluN3A977D (LQY/AAA) showed a trend toward decreased endocytosis. Defective internalization of TacGluN3A977D (YWL/AAA) was associated with an accumulation at the cell surface $(434 \pm 72 \%$ relative to TacGluN3A977 $\Delta$ ), which was similar in magnitude to that displayed by the TacGluN3A966 $\Delta$ mutant (Fig. 1E). Importantly, for this and all other constructs, surface accumulation correlated well with defective internalization, validating surface expression as a reliable parameter for evaluating endocytosis (Fig. $1 D, E$ ).

Within the YWL subset, mutating the WL residues to alanines inhibited internalization to almost the same extent as mutation of all three residues (36\% of TacGluN3A977D (WL/AA)expressing cells showed internalization, $p<0.001$ ), while single-site mutation of Y971 (Y971A) yielded only a partial, nonsignificant inhibition of endocytosis (Fig. $2 C)$. Despite their much reduced internalization, both TacGluN3A966 $\Delta$ and TacGluN3A977 (YWL/AAA) displayed residual internalization, which was completely abolished by additionally mutating an upstream dileucine sequence (L958A, L959A) (Fig. $2 B, D$ ). Together, these data demonstrate that the YWL motif within the GluN3A C terminus plays a major role in the internalization of TacGluN3A in heterologous cells, with a lesser contribution of an additional dileucine motif. A sequence alignment of the 26 aa immediately following the fourth transmembrane domain of human, rat, mouse, and zebrafish GluN3 revealed that the YWL motif, but not the dileucine, is highly conserved across species and is shared by both GluN3A and GluN3B subunits (Fig. 2A).

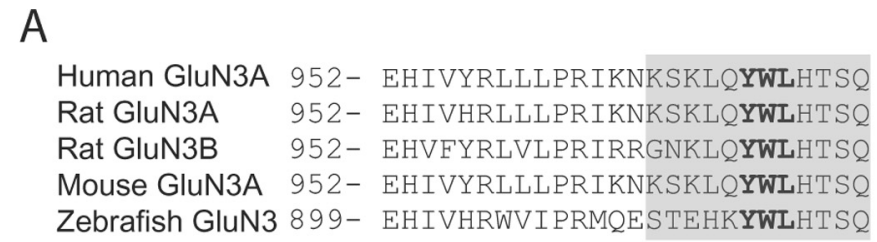

$\mathrm{B}$

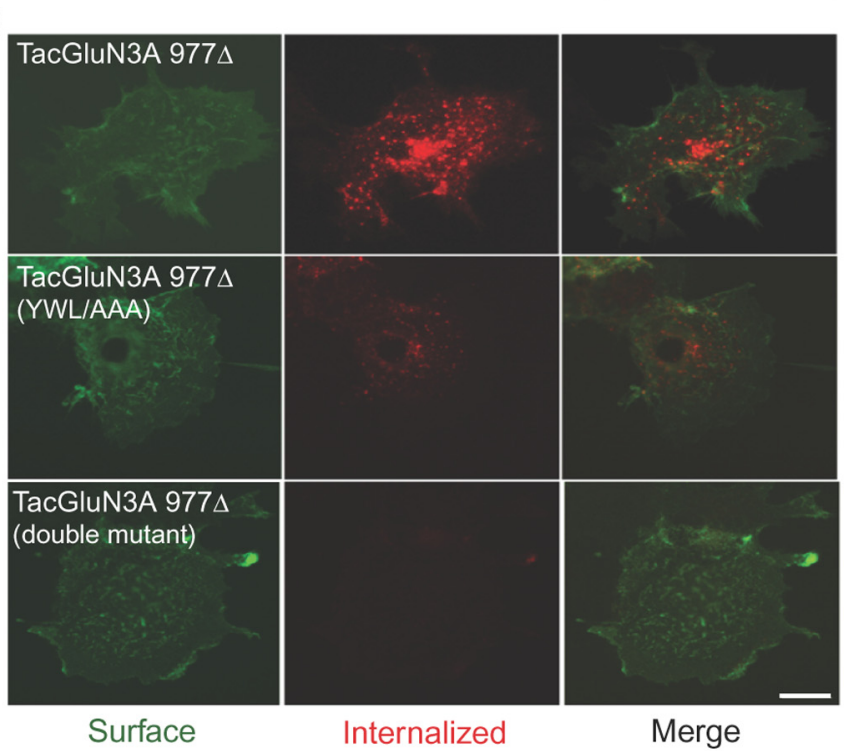

C

Amino acids 966 to 977
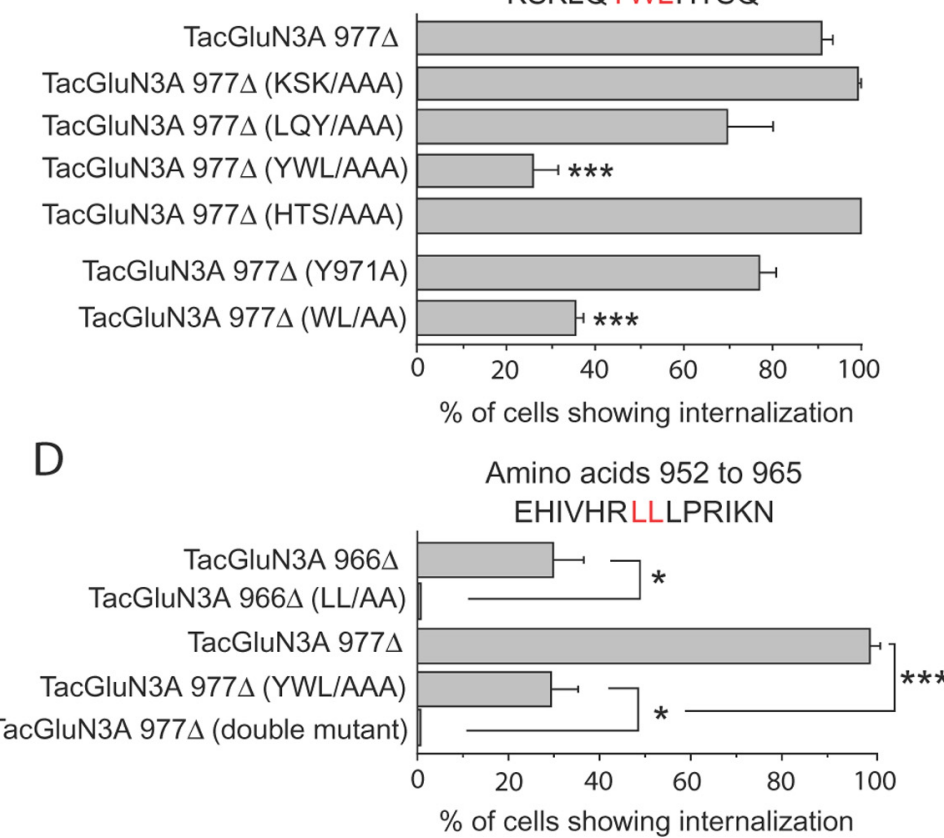

Figure 2. A YWL motif proximal to the fourth transmembrane domain is critical for TacGluN3A endocytosis. $A$, The membrane-proximal region of the GluN3A C terminus spanning the 966-977 aa stretch required for internalization (shaded) contains a tyrosine-based signal (in bold), which is highly conserved across species. B, C, Alanine substitutions of residues within this endocytic domain demonstrate a critical role of the YWL motif in GluN3A endocytosis. $\boldsymbol{B}, \boldsymbol{D}$, Residual internalization of TacGluN3A977 $\Delta$ (YWL/AAA) was abolished by additional mutation of a dileucine sequence upstream of the YWL motif. Internalization assays and quantification were performed as in Figure 1; red intracellular puncta represent internalized proteins while surface immunostaining is shown in green $(n=180-300$ cells analyzed from 3 to 5 independent experiments; ${ }^{* * *} p<0.001$ relative to TacGluN3A977 $\Delta,{ }^{*} p<0.05$ relative to the indicated control group; ANOVA followed by Tukey's test). Scale bar, $20 \mu \mathrm{m}$. 
A

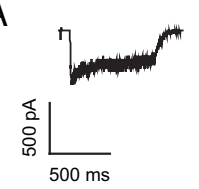

GluN1/2A/3A

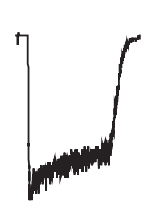

GluN1/2A/3A (YWL/AAA)
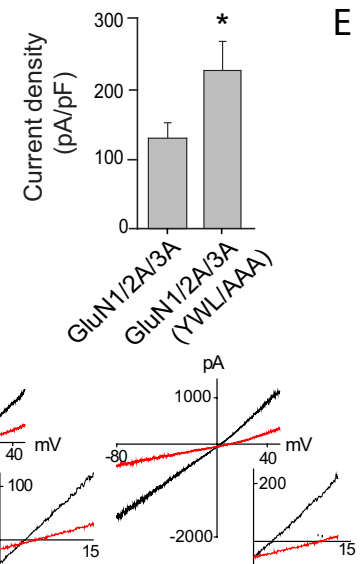

GluN1/2A

E

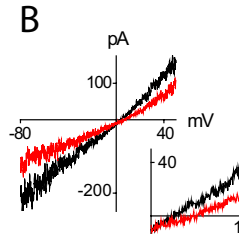

GluN1/2A/3A
GluN1/2A/3A (YWL/AAA)

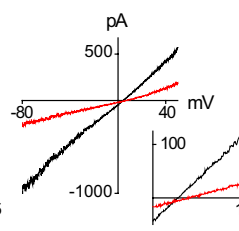

D

C

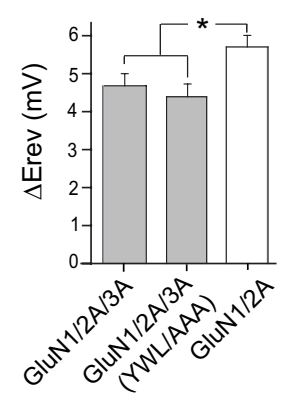

$\mathrm{D}$

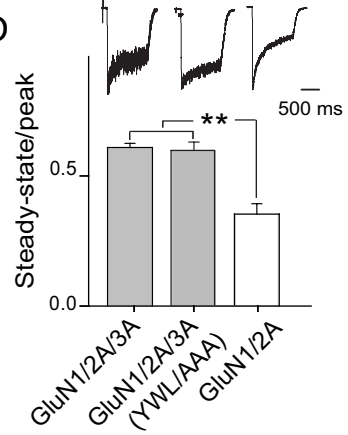

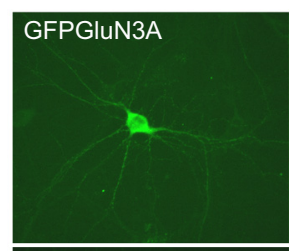

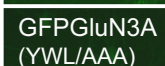

(YWL/AAA)

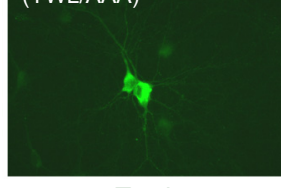

Total

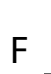

F

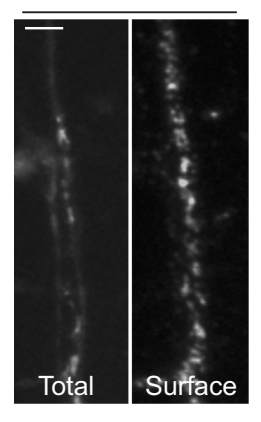

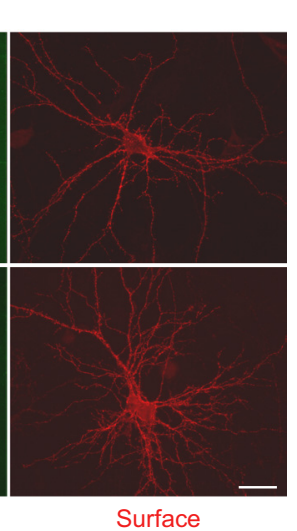

G

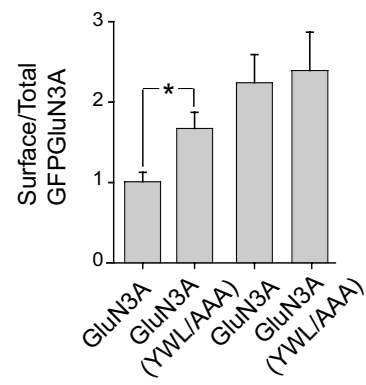

$\operatorname{TTX} 1 \mu \mathrm{M} \quad-\quad+\quad+$

$\mathrm{H}$
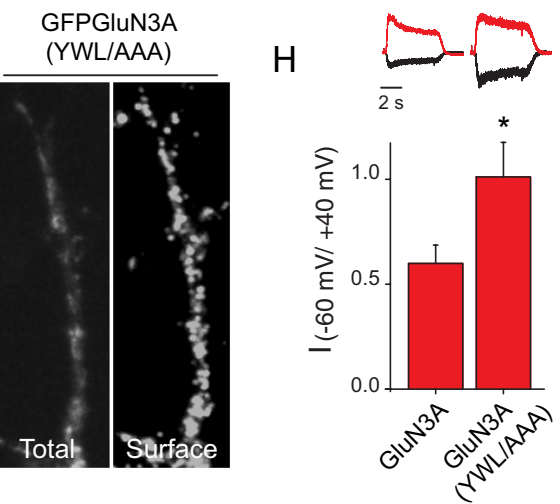

Figure 3. Mutation of the YWL endocytic motif alters the surface expression of GluN3A-containing NMDARs. A-D, HEK293 cells were transfected with wild-type or endocytosis-deficient GFPGluN3A along with GluN1-1a and GluN2A and subjected to whole-cell recordings. $A$, Left, Representative traces in response to $1 \mathrm{~s} \mathrm{pulse} \mathrm{of} \mathrm{glutamate} \mathrm{(1} \mathrm{mm)} \mathrm{and} \mathrm{glycine} \mathrm{(100} \mu \mathrm{m}$ ). Right, Summary graph comparing current densities of cells expressing wild-type GluN3A and YWL/AAA mutant. Current density was calculated as the peak amplitude of initial currents ( $p A$ ) normalized by membrane capacitance (pF). B, Representative steady-state I-V relationships in $2 \mathrm{~mm} \mathrm{Ca}^{2+}$ (red) or $10 \mathrm{~mm} \mathrm{Ca}^{2+}$ (black) for the indicated subunit combinations are shown. Insets, Expanded views of the region of the I-V curves near $E_{\text {rev }}$ C, Summary graph of the shift in reversal potential $\left(\Delta E_{\text {rev }}\right.$ ) determined from the steady-state I-V relations for GluN1/2A and GluN1/2A/3A (wild-type vs YWL/AAA mutant). $D$, Summary graph of the extent of desensitization for recombinant NMDARs calculated as the steady-state/peak current elicited in response to agonist application. Representative traces appear above the corresponding column ( $n=13-16$ cells per condition, ${ }^{*} p<0.05,{ }^{* *} p<0.01$, Student's $t$ test). E, Cultured hippocampal neurons expressing GFPGluN3A or GFPGluN3A (YWL/AAA) were incubated live with anti-GFP antibody to label surface receptors (red). Green fluorescence was used to estimate total GFPGluN3A expression. Scale bar, $20 \mu m$. $\boldsymbol{F}$, Higher magnification images of total and surface GFPGluN3A expression in dendritic compartments of transfected neurons. Scale bar, $5 \mu \mathrm{m}$. $\mathbf{G}$, Quantification of GluN3A surface expression normalized to total GFPGluN3A fluorescence intensities. Note that mutation of the YWL motif increased surface GluN3A levels, and that this effect was mimicked and occluded by chronic activity blockade for $72 \mathrm{~h}$ with TTX ( $n=37-41$ neurons analyzed from 3 to 4 independent experiments, ${ }^{*} p<0.05$, Student's $t$ test). $\boldsymbol{H}$, Summary graph of the ratio of NMDA-evoked currents obtained at -60 mV to +40 $\mathrm{mV}$ in the presence of $100 \mu \mathrm{m} \mathrm{Mg}{ }^{2+}$ for hippocampal neurons transfected with either GFPGluN3A $(n=10)$ or GFPGluN3A (YWL/AAA) ( $\left.n=8\right)$, ${ }^{*} p<0.05$, Student's $t$ test. Representative traces at $-60 \mathrm{mV}$ (black traces) and $+40 \mathrm{mV}$ (red traces) for each condition normalized to their respective currents at $+40 \mathrm{mV}$.

The GluN3A endocytic motif controls the functional surface expression of GluN3A-containing triheteromeric receptors To test whether the YWL endocytic motif plays a role in controlling the functional surface expression of fully assembled NMDARs, we analyzed the electrophysiological responses to acutely applied glutamate in HEK293 cells expressing GFPGluN3A (with or without alanine mutations of the YWL motif) along with GluN1-1a and GluN2A. Previous electrophysiological studies in oocytes and HEK293 cells showed that introduction of the GFP tag does not alter the functional incorporation or biophysical properties of GluN3A-containing NMDARs (Pérez-Otaño et al., 2001; Burzomato et al., 2010). This was further confirmed by surface biotinylation studies that showed equivalent surface expression of untagged and GFPtagged GluN3A in HEK293 cells upon cotransfection with GluN1-1a (data not shown).

We found that the YWL/AAA mutation yields a nearly twofold increase in glutamate-evoked currents (GluN1/2A/3A: $127.0 \pm 22.7 \mathrm{pA} / \mathrm{pF}$ vs GluN1/2A/3A (YWL/AAA): $231.6 \pm 42.7$
pA/pF; $p<0.05$; Fig. 3A). Coexpression of GluN1-1a, GluN2A, and GluN3A subunits in heterologous expression systems yields a mixed population of GluN1/2A and GluN1/2A/3A channels, whose relative contribution to the whole-cell current can be assessed by the magnitude of the shift in reversal potential $\left(\Delta E_{\mathrm{rev}}\right)$ measured during steady-state $\mathrm{I}-\mathrm{V}$ relations obtained via a voltage ramp protocol in 2 and $10 \mathrm{~mm}$ extracellular $\mathrm{Ca}^{2+}$ (Pérez-Otaño et al., 2001, 2006). Measurements of $\Delta E_{\text {rev }}$ revealed that the increased current for the YWL/AAA mutant was likely caused by an accumulation of surface GluN1/2A/3A channels rather than an increase in the GluN1/2A subpopulation, because adding GluN1/2A channels would have increased the $\Delta E_{\text {rev }}$ (Pérez-Otaño et al., 2006) and no such increase was detected (GluN1/2A/3A: $4.68 \pm 0.32 \mathrm{mV}$ vs GluN1/2A/3A (YWL/AAA): $4.39 \pm 0.34 \mathrm{mV}$; Fig. $3 B, C)$. In addition, we found that GluN3A-containing receptors exhibit less desensitization than GluN3A-lacking receptors, as measured by the ratio of steady-state to peak current evoked in response to a $1 \mathrm{~s}$ application of glutamate/glycine (GluN1/2A/3A: $0.61 \pm 0.02$ vs GluN1/2A: $0.35 \pm 0.04 ; p<0.01$; Fig. $3 D)$. But, the 
extent of desensitization $(0.59 \pm 0.03)$ for the YWL/AAA mutant was indistinguishable from wild-type GluN3A (Fig. 3D). This analysis shows that mutating the YWL motif promotes the surface accumulation of functional GluN3A-containing NMDARs, consistent with the defective endocytosis and surface accumulation exhibited by the mutant in Tac antibody uptake assays.

We confirmed that the YWL motif can serve an equivalent role in neurons with both immunocytochemical and electrophysiological techniques. We analyzed GluN3A surface expression by measuring extracellular anti-GFP immunoreactivity in primary hippocampal neurons transfected with wild-type or mutant GFPGluN3A; see Pérez-Otaño et al., 2006 for evidence that transfected GFPGluN3A assembles with endogenous NMDAR subunits to permit cell surface delivery in this system. The YWL/AAA mutation increased the steady-state surface levels of GFPGluN3A, measured across the entire neuron including the soma $(p<0.05$ relative to wild-type; Fig. $3 E, G)$. This result was confirmed by measurements of only dendritic surface levels (Fig. 3F; GFPGluN3A: $2.58 \pm 0.32$ vs GFPGluN3A (YWL/AAA): $4.51 \pm 0.64, n=8 ; p=0.017)$. For electrophysiological experiments, we measured the ratio of NMDAR response sizes obtained at $-60 \mathrm{mV}$ and $+40 \mathrm{mV}$ in the presence of $100 \mu \mathrm{M} \mathrm{Mg}^{2+}$. The YWL/AAA mutation caused a robust increase in this ratio (GFPGluN3A: $0.60 \pm 0.09$ vs GFPGluN3A (YWL/AAA): $1.01 \pm 0.17$; $p<0.05$, Fig. $3 H$ ) indicating reduced sensitivity to $\mathrm{Mg}^{2+}$ blockade at negative voltages, which is a defining characteristic of GluN3A-containing receptors (Tong et al., 2008). These results show that the YWL/ AAA mutation increases the surface and functional expression of GluN3A-containing receptors in neurons, as expected if the mutation blocks ongoing GluN3A endocytosis.

We had previously shown that tonic neuronal activity is required for GluN3A endocytosis, which could be blocked by the sodium channel blocker TTX leading to enhanced surface GluN3A expression (Pérez-Otaño et al., 2006). Intriguingly, the YWL mutation largely occluded the ability of TTX to increase GluN3A surface expression (Fig. 3G), suggesting that neuronal activity may use this site to drive GluN3A endocytic removal. Together, our results demonstrate that the YWL motif is a critical determinant for GluN3A endocytosis that functions in both neurons and heterologous expression systems to regulate the surface expression of GluN3A-containing NMDARs.

\section{Clathrin-dependent endocytosis mediates GluN3A internalization}

Clathrin-mediated endocytosis constitutes a major cellular mechanism for internalization of cell surface receptors, and critically requires the clathrin adaptor complex AP2 and the GTPase dynamin. To test whether GluN3A internalizes via clathrindependent pathways, we first used a dominant-negative mutant of dynamin 1 that lacks GTPase activity (DynK44A) (Damke et al., 1994). Coexpression of DynK44A blocked TacGluN3A endocytosis (Fig. 4A). Second, we used RNA interference to knockdown the AP2 complex, which is comprised of four subunits: $\alpha, \beta 2, \sigma 2$, and $\mu 2$ adaptins (Bonifacino and Traub, 2003). Immunoblot analysis showed that transfection of siRNAs against $\mu 2$ subunits of AP2 (Fraile-Ramos et al., 2003) depleted $\mu 2$ expression only partially, as a result of large cellto-cell variability (Fig. 4B). Nevertheless, AP2-depleted cells could be readily identified by a deficiency in transferrin (Tf) uptake and loss of the characteristic punctate distribution of $\alpha$-adaptin, indicating disruption of AP2 complexes (Fig. $4 C$ ) (Motley et al., 2003). Single-cell internalization assays where deficiency in Tf uptake was used to verify AP2 depletion showed that TacGluN3A endocytosis was abolished in AP2depleted cells ( $p<0.01$ vs control cells; Fig. $4 D, E)$. The dual requirement for intact dynamin and AP2 function strongly 


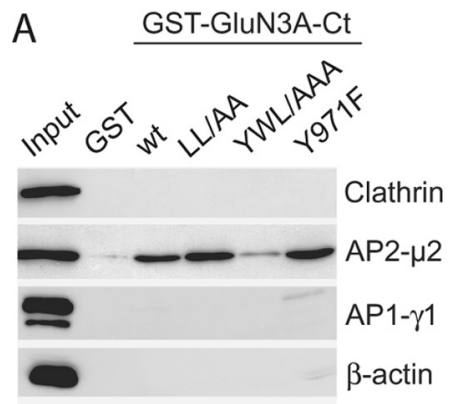

B
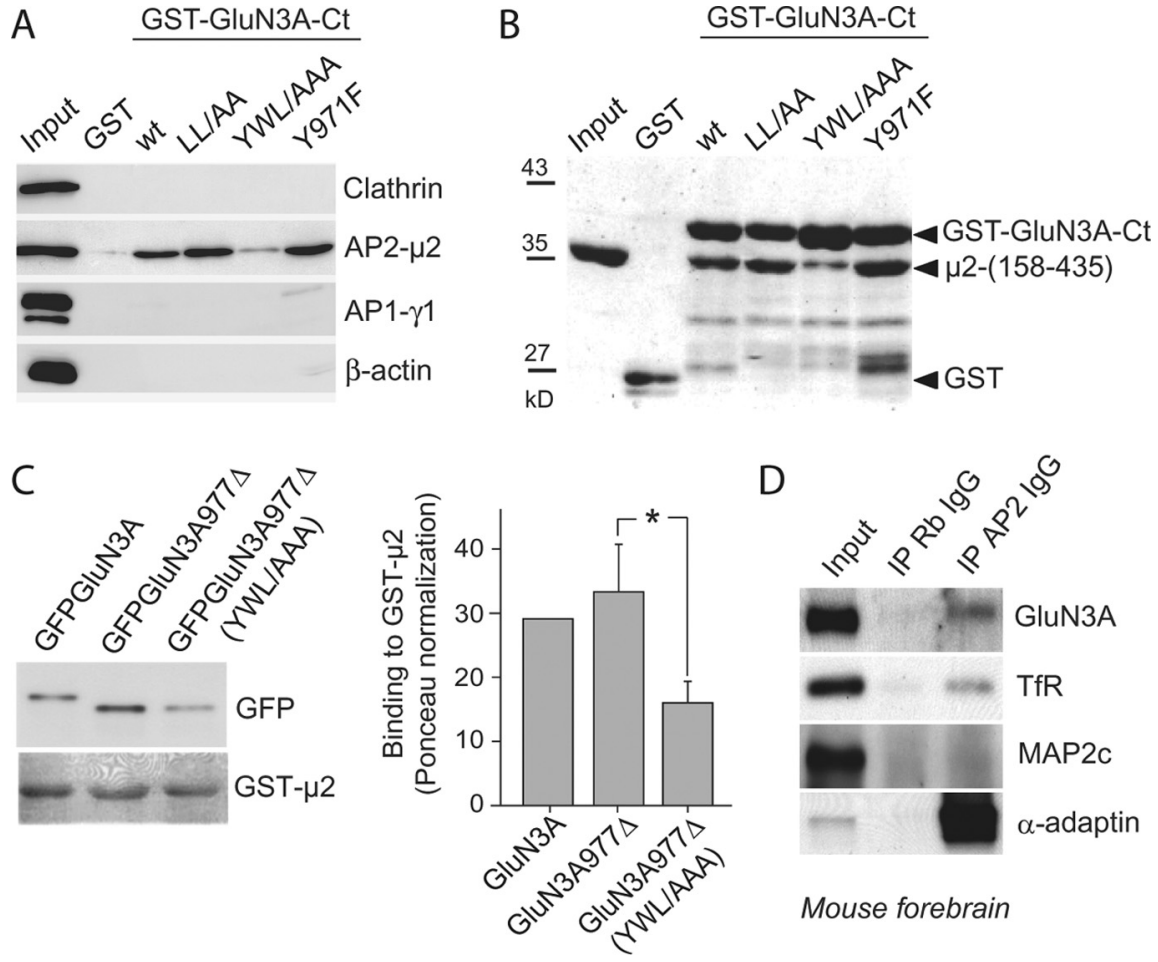

Mouse forebrain

Figure 5. GluN3A interacts with the $\mu 2$ subunit of AP2 adaptor complex. A, The GluN3A C terminus (GluN3A-Ct) specifically binds the $\mu 2$ subunit of AP2. The YWL/AAA mutant largely reduced the interaction whereas neither a single point mutation of the tyrosine within YWL (Y971F) nor mutation of the LL residues (LL/AA) altered binding. GST, GST fused to wild-type GluN3A-Ct (GST-GluN3A-Ct) or endocytosis-deficient versions were incubated with forebrain lysates and the bound material was analyzed by immunoblotting for the indicated proteins; input, $1 \%$ of forebrain lysate used for incubation. B, Direct binding of the GluN3A-Ct to recombinant $\mu 2$. Wild-type or mutant GST-GluN3A-Ct was incubated with purified His-tagged $\mu 2$ (amino acids 158-435), and bound material was analyzed by SDS-PAGE followed by Coomassie blue staining. The arrowheads denote the GST fusion proteins and bound $\mu 2$. Input, $20 \%$ of the total amount of recombinant $\mu 2$ added to the assay. Molecular weights (in $\mathrm{kD}$ ) are indicated. $\boldsymbol{C}$, Recombinant $\mu 2$ (amino acids 158 - 435) fused to GST (GST- $\mu 2$ ) was incubated with extracts from HEK293 cells transfected with GFPGluN3A or GFPGluN3A977 $\Delta$ with or without alanine mutations of the YWL motif. Bound material was analyzed by immunoblotting with anti-GFP antibody, and GST fusion proteins visualized with Ponceau S. The graph shows the quantification of the amount of GFPGluN3A bound to GST- $\mu 2$; Ponceau-stained bands were used for normalization ( $n=4,{ }^{*} p<0.05$, Student's $s$ test) D, Association of endogenous GluN3A and AP2 in mouse forebrain. Solubilized forebrain membrane extracts were incubated with antibody against $\alpha$-adaptin (AP2) or rabbit (Rb) lgG and immunoprecipitates (IP) immunoblotted with the indicated antibodies. Input, $10 \%$ of brain extract used for IP.

indicates that GluN3A enters cells via clathrin-mediated endocytosis (McMahon and Boucrot, 2011).

A key step initiating clathrin-mediated receptor endocytosis is the interaction of intracellular domains of cargo proteins with AP2, either directly or via bridging accessory proteins (Ohno et al., 1995). To test whether GluN3A interacts with AP2, we fused the GluN3A C terminus (GluN3A-Ct) to GST and used the purified fusion protein (GST-GluN3A-Ct) adsorbed to glutathione agarose beads in pull-down assays. GST-GluN3A-Ct, but not GST alone, effectively pulled down native AP2- $\mu 2$ from rat brain lysates (Fig. 5A). Binding was specific because related proteins such as clathrin, AP1- $\gamma 1$, or $\beta$-actin did not interact with GSTGluN3A-Ct (Fig. 5A). To find out whether the GluN3A-Ct binds directly to the $\mu 2$ subunit of AP2, which serves as a major site for membrane protein interactions with AP2 complexes, we incubated purified $\mathrm{His}_{6}$-tagged $\mu 2$ (amino acids $158-435$ ) with GSTGluN3A-Ct or GST. As shown in Figure $5 B$, recombinant His $_{6}-\mu 2$ robustly bound to GST-GluN3A-Ct but not to GST, indicating a direct and specific interaction. Alanine mutations of the YWL endocytic motif impaired GluN3A-Ct interaction with both recombinant purified and brain-derived $\mu 2$, while mutating the dileucine sequence (L958A, L959A) had no effect (Fig. 5A,B).

A single point mutation of Y971 within the endocytic motif (Y971F) did not alter AP2 interaction in either in vitro assay. This behavior differs from mutation of tyrosine residues in classical AP2 binding tyrosine-based motifs (Ohno et al., 1996), but is consistent with the weaker effect of the Y971 mutation on TacGluN3A endocytosis (Fig. 2C) and with the YWL motif being noncompliant with the consensus YXXØ sequence for AP2 binding (in which $\mathrm{X}$ is any amino acid and $\varnothing$ a bulky hydrophobic residue).

To test whether the full-length GluN3A protein interacts with AP2- $\mu 2$, we expressed GFPGluN3A in HEK293 cells and devised a reciprocal pull-down assay using a GST- $\mu 2$ (amino acid 158435) fusion protein. As shown in Figure $5 C$, GFPGluN3A was efficiently pulled down by GST- $\mu 2$. Deleting amino acids 978-1115 of GluN3A, distal to the endocytic domain (GFPGluN3A 977 ), did not affect binding, confirming that the membrane-proximal domain of GluN3A $\mathrm{C}$ terminus harboring the endocytic motif is sufficient to bind AP2 in agreement with our internalization results. Mutation of the YWL motif impaired this interaction ( $p<0.05$ vs GluN3A977 $\Delta$; Fig. $5 C$ ), as seen in the context of the isolated GluN3A-Ct. Together, the results demonstrate a direct interaction between AP2- $\mu 2$ and the C terminus of GluN3A and identify the YWL endocytic motif as a key determinant of AP2 binding. Finally, an antibody against $\alpha$-adaptin coprecipitated endogenous GluN3A from brain membrane extracts (Fig. 5D), demonstrating association between native AP2 and GluN3A in the brain. Tf receptor (TfR), known to undergo clathrin-dependent endocytosis (but not microtubule-associated protein 2c (MAP2c), an abundant intracellular protein) was found in the immunoprecipitate.

\section{Y971 within the GluN3A endocytic motif is phosphorylated by the tyrosine kinase Src}

Because phosphorylation is a fundamental mechanism to regulate membrane protein trafficking to and from the cell surface (Chen and Roche, 2007), we next investigated whether GluN3A undergoes tyrosine phosphorylation and, specifically, whether Y971 within the endocytic motif is a substrate for phosphorylation. Initial experiments assessed the phosphorylation status of GFPGluN3A expressed in HEK293 cells after inhibition of endogenous tyrosine phosphatases with pervanadate (Heiska and Carpén, 2005). GFPGluN3A was immunoprecipitated with an anti-GFP antibody and the immunoprecipitate probed with antiphosphotyrosine antibody; the identity of the phosphotyrosine band was verified by reprobing with anti-GluN3A antibody. Following pervanadate treatment for $15 \mathrm{~min}$, GluN3A was readily phosphorylated in a dose-dependent manner (Fig. 6A).

SFKs, specifically Src and Fyn, have been shown to directly phosphorylate NMDAR subunits, enhancing NMDAR function 
and modulating the induction of synaptic plasticity (Groveman et al., 2012; Trepanier et al., 2012). To evaluate their roles in GluN3A phosphorylation, a constitutively active Y527F mutant (Src-YF) or a kinase-dead mutant (Src-KD) of Src was coexpressed with GFPGluN3A in HEK293 cells. GFPGluN3A was phosphorylated only in cells coexpressing Src-YF (Fig. 6B). Coexpression of a constitutively active form of Fyn also led to GluN3A phosphorylation, but was less effective than Src-YF (data not shown). To determine whether tyrosine phosphorylation of native GluN3A occurs in vivo, mouse forebrain extracts were incubated with anti-phosphotyrosine antibody. Immunoblot with an antibody against GluN3A demonstrated the presence of GluN3A in the immunoprecipitate (Fig. $6 C)$, showing that GluN3A undergoes tyrosine phosphorylation in the brain.

To determine whether Y971 within the GluN3A endocytic motif is phosphorylated, we performed in vitro phosphorylation assays where wild-type GST-GluN3A-Ct, or mutants with either Y971 alone or all three tyrosine residues in the GluN3A-Ct substituted by phenylalanines, was incubated with recombinant Src in the presence of $\left[\gamma_{-}{ }^{32} \mathrm{P}\right]$ ATP. Autoradiographs of the reaction mixtures separated by SDS-PAGE revealed substantial Src-dependent incorporation of ${ }^{32} \mathrm{P}$ into the GluN3A C-terminal tail (Fig. 6D). Phosphorylation was significantly reduced by mutating Y971 $(p<0.01$ vs wild-type GluN3A; Fig. 6D) and, as expected, the $3 \mathrm{Y}-3 \mathrm{~F}$ mutant showed no detectable phosphorylation. Collectively, these findings demonstrate phosphorylation of GluN3A in vivo and in vitro for the first time, and identify Y971 within the GluN3A endocytic motif as a direct substrate for Src.

\section{Phosphorylation of Y971 regulates GluN3A endocytosis}

We next asked whether phosphorylation of GluN3A affects its endocytic trafficking. We started by testing whether manipulations of tyrosine phosphorylation alter surface GluN3A levels using surface biotinylation assays in HEK293 cells transfected with GluN1-1a and GluN3A. Increasing cellular tyrosine phosphorylation with pervanadate decreased surface GluN3A levels by $30 \%$ ( $p<0.01$ vs untreated cells; Fig. $7 A$ ); note that GluN3A in the surface fraction appears as a larger molecular size band relative to the total fraction, indicative of higher order processing in the secretory pathway (Pérez-Otaño et al., 2001). Tubulin, a cytosolic protein, was absent from the surface fraction, confirming that only surface proteins were recovered in our assay. Importantly, the effect of pervanadate was blocked by the phosphodefective mutant GluN3A-Y971F (Fig. 7A), consistent with pull-down assays that showed lesser binding of GFPGluN3AY971F to GST- $\mu 2$ upon pervanadate treatment $(p<0.05$ relative to wild-type; Fig. $7 B$ ). Experiments in cultured cortical neurons further confirmed a phospho-modulation of GluN3A binding to $\mathrm{AP} 2$, as shown by an increase in the amount of AP2 that was coimmunoprecipitated by an anti-GluN3A antibody in pervanadate-treated neurons compared with untreated ones (Fig. 7C).

To further analyze the effect of Y971 phosphorylation, we generated a phosphomimetic mutant (GluN3A-Y971E) and analyzed its surface expression using biotinylation assays as above. The Y971E mutation caused a large reduction in surface GluN3A relative to wild-type $(p<0.01$; Fig. $7 D)$ that was associated with an increased ability of the mutant to bind both $\alpha$ - and $\mu 2$ adaptins in GST pull-down assays $(p<0.05$; Fig. $7 E)$. We also evaluated the ability of the phosphomimetic mutant to regulate recombinant NMDAR currents in HEK293 cells. The Y971E mutation significantly increased the $\Delta E_{\mathrm{rev}}$ (GluN3A-Y971E: $6.17 \pm$ $0.34 \mathrm{mV}, p<0.05$; Fig. $7 F)$ as well as the extent of desensitization $(0.29 \pm 0.02, p<0.01$; Fig. $7 G)$ compared with wild-type GluN3A. In both cases, the Y971E mutation shifted these biophysical parameters to levels similar to those measured in GluN1/ $2 \mathrm{~A}$-expressing cells, indicating a reduction in the proportion of GluN3A-containing surface-expressed channels that closely resembles the functional effect of enhancing GluN3A endocytosis via PACSIN1 coexpression (Pérez-Otaño et al., 2006). Additional control experiments showed that none of the mutations in the YWL motif (YWL/AAA, Y971F, Y971E) altered total GluN3A protein expression or GluN3A assembly with GluN1 or GluN2A subunits in transfected HEK293 cells, ruling out a contribution of 


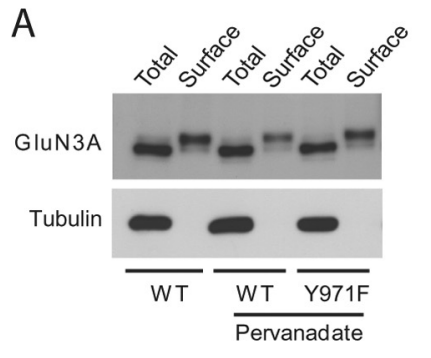

D

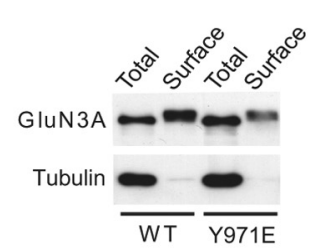

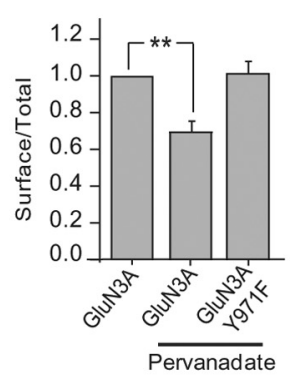

$\mathrm{E}$
B

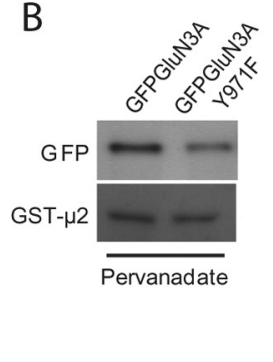

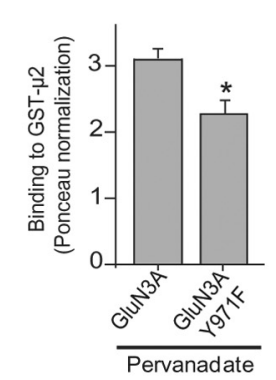

$\mathrm{F}$

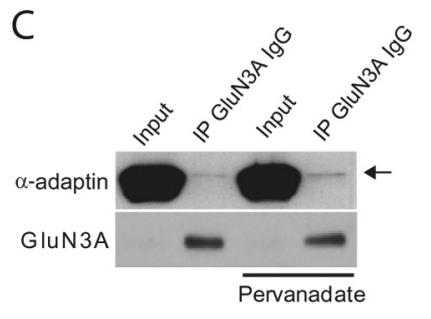

Cortical neurons
GST-

GluN3A-Ct
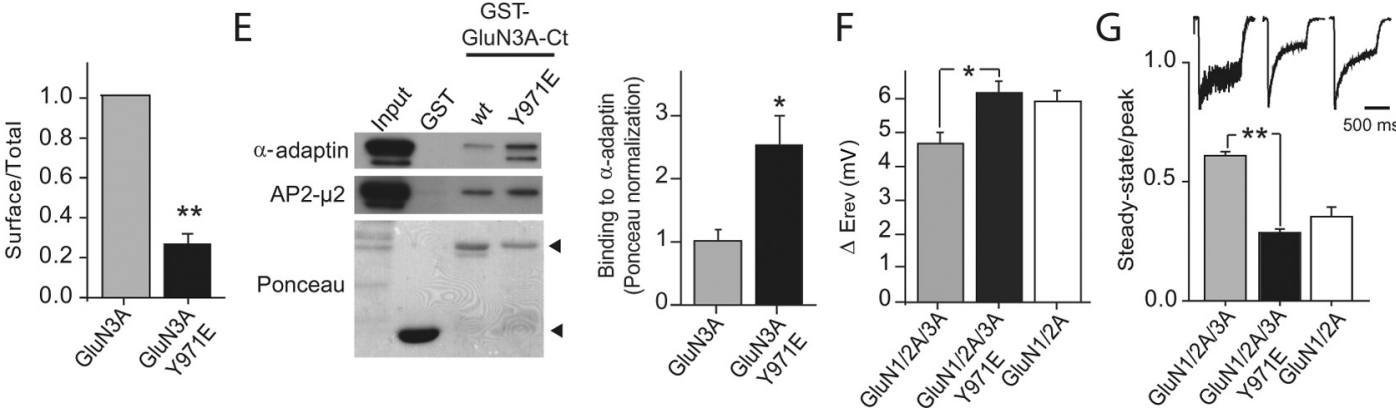

Figure 7. Increased phosphorylation reduces surface GluN3A expression by modulating AP2 binding. A, HEK293 cells expressing wild-type GluN3A or phospho-defective Y971F mutant along with GluN1-1a were treated with pervanadate $(150 \mu \mathrm{m})$ for $15 \mathrm{~min}$. Surface proteins were biotinylated and isolated with NeutrAvidin-agarose beads, and total and surface fractions analyzed by immunoblotting with anti-GluN3A antibody. The absence of the intracellular protein tubulin from the surface fraction confirmed that only surface proteins were recovered. The graph shows quantification of surface GluN3A ( $n=3$ independent experiments, ${ }^{* *} p<0.01$, Student's $t$ test). $\boldsymbol{B}$, Pull-down assays using GST- $\mu 2$ and extracts from HEK293 cells expressing GFPGluN3A or GFPGluN3A-Y971F mutant. Bound material was analyzed by immunoblotting with anti-GFP antibody. Graph shows quantification; Ponceau-stained bands of GST- $\mu 2$ from same blot were used for normalization ( $n=4$ independent assays, ${ }^{*} p<0.05$, Student's $t$ test). C, Association of GluN3A with AP2 was monitored in cortical neuronal cultures treated with pervanadate (200 $\mu \mathrm{M}$, 15 min). Cell lysates were incubated with anti-GluN3A antibody, and immunoprecipitates were immunoblotted with $\alpha$-adaptin and GluN3A antibodies. Input, $10 \%$ of lysate. D, Surface biotinylation assay in HEK293 cells expressing wild-type GluN3A or the phosphomimetic Y971E mutant along with GluN1-1a. Surface and total fractions were analyzed as above. Graph shows quantification of surface GluN3A ( $n=3,{ }^{* *} p<0.01$, Student's $t$ test). E, Pull-down assays using mouse brain lysates and GST, wild-type GST-GluN3A-Ct, or GST-GluN3A-Ct-Y971E mutant. Bound material was analyzed by immunoblotting with antibodies against $\alpha$-and $\mu 2$-adaptins. Ponceau-stained bands of GST fusion proteins (arrowheads) were used for normalization of the immunoreactivity within each lane. Graph shows quantification of the amount of $\alpha$-adaptin pulled down by GST-GluN3A fusion proteins $\left(n=3,{ }^{*} p<0.05\right.$, Student's $t$ test). $\boldsymbol{F}, \mathbf{G}$, Whole-cell recordings from HEK293 cells expressing either wild-type GluN3A or GluN3A-Y971E along with GluN1-1a and GluN2A. $\boldsymbol{F}$, Summary graph of the shift in reversal potential $\left(\Delta E_{\text {rev }}\right)$ of NMDAR currents measured in low and high extracellular $\mathrm{Ca}^{2+}$ ( $n=10$ cells per condition, ${ }^{*} p<0.05$, Student's $t$ test). G, Summary graph of the extent of NMDAR current desensitization. Normalized representative traces in response to agonist application appear above the corresponding column ( $n=10-16$ cells, ${ }^{* *} p<0.01$, Student's $t$ test).

these factors to the surface and functional changes caused by the mutations (data not shown). Collectively, these biochemical and electrophysiological data demonstrate that: (1) increasing tyrosine phosphorylation reduces GluN3A surface expression and promotes a switch from GluN3A-containing to GluN3A-lacking NMDARs, likely via modulation of GluN3A binding to AP2 and (2) identify Y971 within the GluN3A internalization motif as the site for such regulation.

In a final set of experiments, we tested whether tyrosine phosphorylation influences GluN3A endocytosis and surface expression in neurons. First, we measured surface levels of GluN3A-containing NMDARs in hippocampal neurons transfected with wild-type GFPGluN3A or the phosphomimetic mutant. As in heterologous systems, surface levels of GFPGluN3AY971E were reduced relative to wild-type, both when measured across the entire neuron ( $p<0.05$; Fig. $8 A)$ or in dendritic compartments (GFPGluN3A: $2.04 \pm 0.19$ vs GFPGluN3A-Y971E: $1.38 \pm 0.12, n=8 ; p=0.01)$. In complementary electrophysiological experiments the Y971E mutant produced a small, nonsignificant decrease in the $-60 \mathrm{mV} /+40 \mathrm{mV}$ ratio of NMDAR currents recorded in $100 \mu \mathrm{M} \mathrm{Mg}^{2+}$ when compared with wildtype GluN3A (GFPGluN3A: $0.60 \pm 0.09$ vs GFPGluN3A-Y971E: $0.49 \pm 0.06, n=9 ; p=0.34)$. Our inability to detect a functional decrease in GluN3A-containing receptors with the Y971E mutation might reflect a detection limit: note the smaller magnitude of the decrease in surface GluN3A ( $20 \%)$ caused by mimicking phosphorylation when compared with the nearly twofold in- crease in surface GluN3A that results from blocking overall endocytosis with the YWL/AAA mutant (Fig. 3G). Direct antibodyuptake-based endocytosis assays confirmed that decreased surface expression of GluN3A-Y971E reflects increased endocytosis $(p<0.001$ relative to wild-type; Fig. $8 B$ ), consistent with the enhanced interaction of the mutant $\mathrm{C}$ terminus with AP2.

Because the WL sequence within the endocytic motif seems to be a major determinant for internalization (Fig. 2C) but phosphorylation of Y971 has the ability to modulate both AP2binding and internalization of GluN3A, we additionally tested the relative contribution of phosphorylation to ongoing GluN3A endocytosis in cultured neurons. Blocking tyrosine phosphorylation with PP2, a specific inhibitor of SFK activity, did not affect GluN3A internalization (Fig. $8 B$ ), suggesting a negligible role of phosphorylation in neurons under basal conditions. We then examined whether stimuli that potentiate Src-mediated phosphorylation reduce the surface expression of endogenous GluN3A. We stimulated endogenous Src by application of PACAP-38, which was previously shown to activate Src (Macdonald et al., 2005; Yang et al., 2012), and quantified surface proteins with biotinylation assays. PACAP-38 treatment significantly decreased surface GluN3A ( $p<0.001$; Fig. $8 C, D)$. Surface levels of GluN2B were not affected, demonstrating that the effect of PACAP-38 is specific to GluN3A (Fig. $8 C, D$ ). Importantly, the decrease in surface GluN3A was blocked by inhibiting SFK activity with PP2 (Fig. 8C,D). These data demonstrate that the surface expression of endogenous GluN3A can be regulated by Src acti- 
vation. Based on these findings, we conclude that tyrosine phosphorylation regulates GluN3A trafficking in neurons as well as in heterologous expression systems.

\section{Discussion}

Previous studies identified several endocytic and sorting signals within the $\mathrm{C}$ termini of GluN1 and GluN2 subunits (Roche et al., 2001; Lavezzari et al., 2004; Scott et al., 2004) that govern NMDAR endocytosis and hence control their surface expression through interactions with scaffolding proteins and/or components of the trafficking machinery (Prybylowski et al., 2005; SanzClemente et al., 2010). Distinct mechanisms appear to control GluN2A and GluN2B endocytosis and trafficking (Barria and Malinow, 2002; Lavezzari et al., 2004; Zhang et al., 2008; Sanz-Clemente et al., 2010), which may be central for ensuring that activity-dependent replacement of GluN2B-containing NMDARs by GluN2Acontaining NMDARs occurs appropriately during synapse maturation. Because GluN3A subunits have similarly been linked to activity-dependent synaptic remodeling, maturation, and plasticity (Roberts et al., 2009), we sought to determine whether GluN3A possessed endocytic motifs that play comparable roles in controlling its cell surface expression. Our results support a model in which clathrin-dependent GluN3A internalization is regulated via phosphorylation of a tyrosine residue (Y971) within the GluN3A intracellular C-terminal tail. Y971 lies within a novel endocytic motif comprising residues 971-973 (YWL), which confers binding to the clathrin adaptor AP2. This site is unique in that its phosphorylation enhances, rather than disrupts, binding to AP2. Consequently, Y971 phosphorylation favors the endocytosis of GluN3A-containing receptors. This new mechanism might play a central role in determining the GluN3A subunit content of surface NMDARs and, in turn, tune synaptic function and plasticity.

Classical endocytic signals recognized by AP2 include tyrosine-based (YXXØ) and dileucine motifs (Kirchhausen, 1999; Bonifacino and Traub, 2003). Among other NMDAR subunits, the distal C terminus of GluN2B contains a canonical tyrosine-based endocytic motif (YEKL) that binds strongly to AP2, whereas no binding of GluN2A to AP2 has been detected despite the presence of a dileucine motif that mediates GluN2A endocytosis (Lavezzari et al., 2003, 2004). Unlike GluN2B, the tyrosine-based internalization signal identified here (YWL) does not conform to the consensus YXXØ sequence. Nevertheless, several lines of evidence support that this novel GluN3A motif represents a bona fide AP2-linked pathway for GluN3A clathrin-mediated endocytosis. First, our
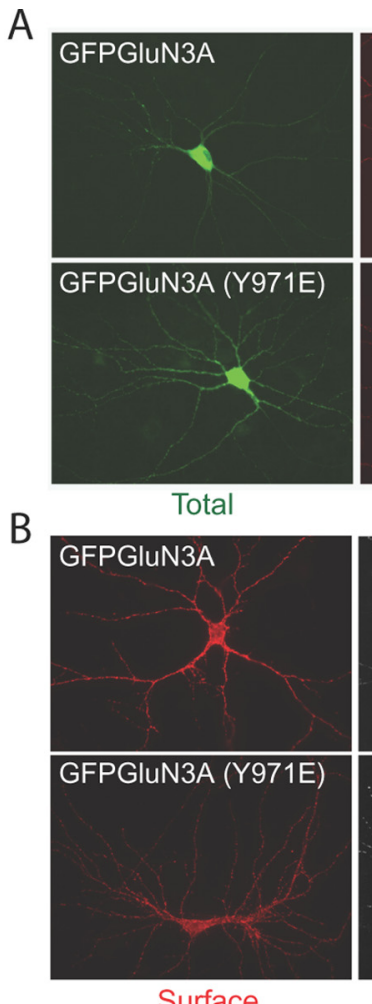

C

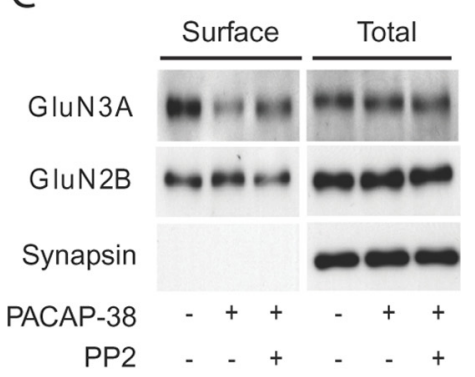

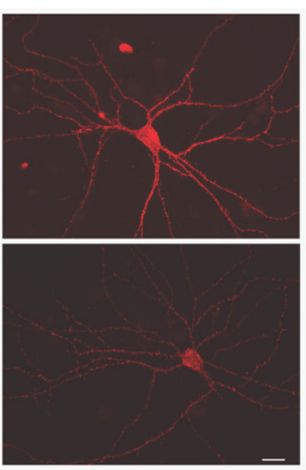

Surface

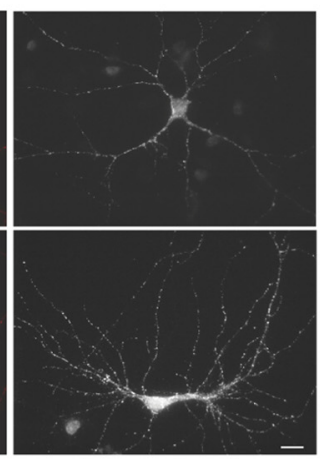

Internalized
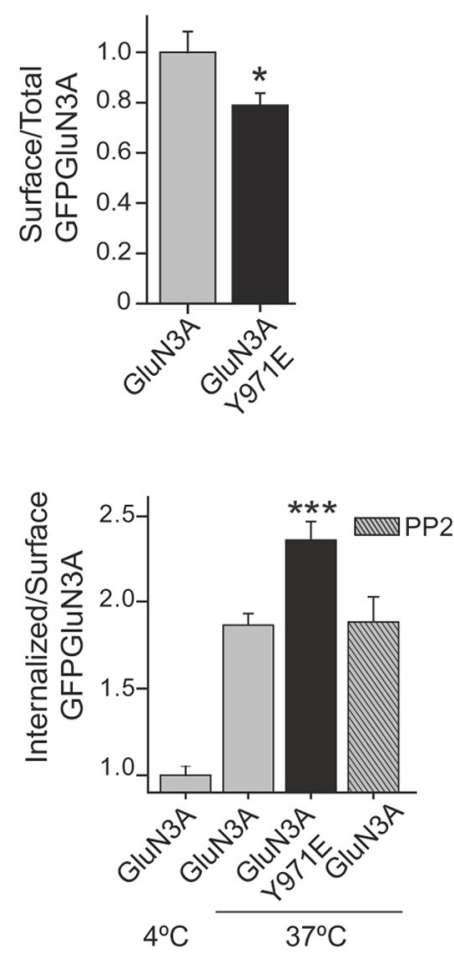

D
Figure 8. Phosphorylation regulates the endocytosis and surface expression of GluN3A in neurons. $\boldsymbol{A}$, Cultured hippocampal neurons transfected with GFPGluN3A or GFPGluN3A-Y971E were incubated live with anti-GFP antibody to label surface receptors (red). Green fluorescence was used to estimate total GFPGluN3A expression. Data represent means of GluN3A surface expression normalized to total GFPGluN3A fluorescence. ( $n=46-52$ neurons from 4 independent experiments per condition, ${ }^{*} p<0.05$, Student's $t$ test). $\boldsymbol{B}$, Internalization was measured using fluorescence-based antibody uptake assays in neurons maintained in normal culture medium at $4^{\circ} \mathrm{C}$ (no endocytosis control) or $37^{\circ} \mathrm{C}$ (basal endocytosis), or in culture medium plus PP2 (10 $\mu \mathrm{m}$ for $15 \mathrm{~min}$ after a $30 \mathrm{~min}$ pre-incubation). Representative images of surface (red) and internalized (white) GFPGluN3A and GFPGluN3A-Y971E are shown. Data represent means of GluN3A endocytosis normalized to its surface expression ( $n=39-40$ neurons from 4 independent experiments, ${ }^{* * *} p<0.001$ relative to wild-type, Student's $t$ test). Scale bar, $40 \mu \mathrm{m}$. C, Cortical cultures (DIV 10) were treated with PACAP-38 (1 nm) for $1 \mathrm{~h}$ after $1 \mathrm{~h}$ pre-incubation with or without PP2 (10 $\mu \mathrm{m})$. Surface proteins were biotinylated, and surface and total fractions analyzed by immunoblotting and probed for the indicated proteins. Absence of the intracellular protein synapsin from surface fractions confirmed the specificity of the assay. $\boldsymbol{D}$, Graphs show quantification of relative surface levels of endogenous GluN3A and GluN2B ( $n=3-7$ independent experiments, ${ }^{* *} p<0.001,{ }^{*} p<0.05$, Student's $t$ test).

biochemical assays demonstrated that the GluN3A C terminus directly interacts with the medium chain subunit of AP2 $(\mu 2)$, which is known to link clathrin to cargo proteins. Second, GluN3A internalization was blocked by both a dominantnegative form of the endocytic GTPase dynamin, as well as by AP2 depletion. Finally, mutations of the YWL endocytic motif largely inhibited AP2 binding and internalization of GluN3Acontaining NMDARs, and drove their accumulation at the cell surface both in heterologous expression systems and primary 
neurons. The YWL motif is shared by GluN3A and GluN3B subunits and might also play a role in the endocytosis of GluN3Bcontaining receptors.

Given the divergence of the YWL motif from the canonical YXXØ sequence it is not surprising that the influence of the tyrosine residue within this motif differs with respect to its ability to bind AP2 and how tyrosine phosphorylation affects this interaction to control endocytosis. Indeed, point mutations of tyrosine within the context of YXXØ motifs are sufficient to abolish AP2 binding (Ohno et al., 1996; Lavezzari et al., 2003) while mutating Y971 alone does not (Fig. 5A,B) and, accordingly, has a small impact on GluN3A internalization and surface accumulation. By phosphorylating NMDAR subunits, SFKs critically control NMDAR function and thereby gate the induction of NMDARdependent plasticity (Salter and Kalia, 2004). Tyrosines within the $\mathrm{C}$ termini of GluN2A and GluN2B subunits are substrates for Src and Fyn SFKs, but the obligatory subunit GluN1 does not appear to be tyrosine phosphorylated suggesting that tyrosine phosphorylation may serve as a source of subtype-specific regulation (Lau and Huganir, 1995; Nakazawa et al., 2001; Taniguchi et al., 2009). In the case of GluN2B, phosphorylation of Y1472 within the YEKL internalization motif by Fyn (Nakazawa et al., 2001) inhibits AP2 binding and internalization of GluN2Bcontaining NMDARs, thus leading to an enhancement of GluN2B-mediated responses (Prybylowski et al., 2005; Nakazawa et al., 2006). Similarly, phosphorylation of GluN2A by Src inhibits endocytosis and enhances surface and synaptic expression of GluN2A-containing NMDARs (Hayashi et al., 2009; Yang et al., 2012). In contrast, our data demonstrate that SFK-mediated phosphorylation of the novel YWL motif within GluN3A favors AP2 binding and internalization of GluN3A-containing receptors. This is supported by in vitro and cellular studies demonstrating that Y971 is a direct substrate for SFKs and that enhancement of its phosphorylation state via phosphomimetic substitution as well as activation of Src decreases GluN3A surface expression. Although this represents a distinctly different outcome from that yielded by manipulation of the tyrosine phosphorylation state of GluN2 receptors, it resembles the favoring of GluA2 AMPAR subunit endocytosis by tyrosine phosphorylation within its internalization domain (Ahmadian et al., 2004).

While our findings provide a mechanistic framework for which GluN3A endocytosis is under control of phosphorylationdependent regulation, a previous study demonstrated that the multifunctional adaptor PACSIN1/syndapin 1 also can selectively promote GluN3A endocytosis and regulate the functional expression of GluN3A-containing NMDARs in an activitydependent manner (Pérez-Otaño et al., 2006). Whether PACSIN1 complements the endocytic mechanism described in this study or functions independently under distinct conditions remains to be explored. However, it is important to note that the GluN3A endocytic motif is sufficient to drive internalization of TacGluN3A chimeras in COS7 cells, which lack PACSIN1, demonstrating that GluN3A internalization can occur independent of PACSIN1 function. Regardless, both phosphorylation of Y971 or PACSIN1 interaction provide mechanisms that foster the activity-dependent removal of GluN3A-containing NMDARs.

Because of the inhibitory role of GluN3A in NMDAR function, phosphorylation-stimulated removal of GluN3Acontaining NMDARs from the surface population might provide a complementary mechanism behind the SFK-mediated enhancement of NMDAR function and its role in initiating longterm forms of synaptic plasticity or gating metaplasticity (Lu et al., 1998; Yang et al., 2012). The use of an atypical tyrosine-based internalization signal can have important functional implications by conferring subunit selectivity and allowing tyrosine phosphorylation to modulate the trafficking and surface expression of GluN3A-containing NMDARs in a manner opposite that of GluN2containing NMDARs. This raises the possibility that activation of SFKs can serve as a common switch regulating the trafficking of GluN3A-lacking and GluN3A-containing NMDARs in opposite directions: SFK activation would promote endocytosis of GluN3A-containing NMDARs, known to limit synapse plasticity and maturation during postnatal brain development (Roberts et al., 2009), while keeping GluN2-containing, GluN3A-lacking subtypes in the neuronal surface. Convergence of both mechanisms would allow efficient replacement of GluN3A-containing NMDARs by $\mathrm{Ca}^{2+}$-permeable subtypes, turning on synaptic plasticity, and allowing neuronal circuit refinement and memory consolidation (Pérez-Otaño and Ehlers, 2005). In summary, our study reveals a trafficking mechanism that contributes to modulate the surface expression of GluN3A-containing NMDARs and might provide a novel means of fine-tuning the cell-surface NMDAR population and in turn, synaptic function and plasticity. Further test of this hypothesis will require to screen whether other SFK-activating stimuli differentially regulate the surface expression and endocytosis of GluN3A-containing versus GluN3A-lacking receptors (as seen for PACAP-38 here), whether Y971 is needed for such differential regulation and, ultimately, test their impact on NMDAR-mediated synapse plasticity and development.

\section{References}

Ahmadian G, Ju W, Liu L, Wyszynski M, Lee SH, Dunah AW, Taghibiglou C, Wang Y, Lu J, Wong TP, Sheng M, Wang YT (2004) Tyrosine phosphorylation of GluR2 is required for insulin-stimulated AMPA receptor endocytosis and LTD. EMBO J 23:1040-1050. CrossRef Medline

Barria A, Malinow R (2002) Subunit-specific NMDA receptor trafficking to synapses. Neuron 35:345-353. CrossRef Medline

Bonifacino JS, Traub LM (2003) Signals for sorting of transmembrane proteins to endosomes and lysosomes. Annu Rev Biochem 72:395-447. CrossRef Medline

Burzomato V, Frugier G, Pérez-Otaño I, Kittler JT, Attwell D (2010) The receptor subunits generating NMDA receptor mediated currents in oligodendrocytes. J Physiol 588:3403-3414. CrossRef Medline

Chen BS, Roche KW (2007) Regulation of NMDA receptors by phosphorylation. Neuropharmacology 53:362-368. CrossRef Medline

Chung HJ, Huang YH, Lau LF, Huganir RL (2004) Regulation of the NMDA receptor complex and trafficking by activity-dependent phosphorylation of the NR2B subunit PDZ ligand. J Neurosci 24:10248-10259. CrossRef Medline

Cull-Candy SG, Leszkiewicz DN (2004) Role of distinct NMDA receptor subtypes at central synapses. Sci STKE 2004:re16. CrossRef Medline

Damke H, Baba T, Warnock DE, Schmid SL (1994) Induction of mutant dynamin specifically blocks endocytic coated vesicle formation. J Cell Biol 127:915-934. CrossRef Medline

Fraile-Ramos A, Kohout TA, Waldhoer M, Marsh M (2003) Endocytosis of the viral chemokine receptor US28 does not require beta-arrestins but is dependent on the clathrin-mediated pathway. Traffic 4:243-253. CrossRef Medline

Groveman BR, Feng S, Fang XQ, Pflueger M, Lin SX, Bienkiewicz EA, Yu X (2012) The regulation of N-methyl-D-aspartate receptors by Src kinase. FEBS J 279:20-28. CrossRef Medline

Hayashi T, Huganir RL (2004) Tyrosine phosphorylation and regulation of the AMPA receptor by SRC family tyrosine kinases. J Neurosci 24:61526160. CrossRef Medline

Hayashi T, Thomas GM, Huganir RL (2009) Dual palmitoylation of NR2 subunits regulates NMDA receptor trafficking. Neuron 64:213-226. CrossRef Medline

Heiska L, Carpén O (2005) Src phosphorylates ezrin at tyrosine 477 and induces a phosphospecific association between ezrin and a kelch-repeat 
protein family member. J Biol Chem 280:10244-10252. CrossRef Medline

Henson MA, Larsen RS, Lawson SN, Pérez-Otaño I, Nakanishi N, Lipton SA, Philpot BD (2012) Genetic deletion of NR3A accelerates glutamatergic synapse maturation. PLoS One 7:e42327. CrossRef Medline

Holton KL, Loder MK, Melikian HE (2005) Nonclassical, distinct endocytic signals dictate constitutive and PKC-regulated neurotransmitter transporter internalization. Nat Neurosci 8:881-888. CrossRef Medline

Kahlfeldt N, Vahedi-Faridi A, Koo SJ, Schäfer JG, Krainer G, Keller S, Saenger W, Krauss M, Haucke V (2010) Molecular basis for association of PIPKI gamma-p90 with clathrin adaptor AP-2. J Biol Chem 285:2734-2749. CrossRef Medline

Kirchhausen T (1999) Adaptors for clathrin-mediated traffic. Annu Rev Cell Dev Biol 15:705-732. CrossRef Medline

Larsen RS, Corlew RJ, Henson MA, Roberts AC, Mishina M, Watanabe M, Lipton SA, Nakanishi N, Pérez-Otaño I, Weinberg RJ, Philpot BD (2011) NR3A-containing NMDARs promote neurotransmitter release and spike timing-dependent plasticity. Nat Neurosci 14:338-344. CrossRef Medline

Lau CG, Zukin RS (2007) NMDA receptor trafficking in synaptic plasticity and neuropsychiatric disorders. Nat Rev Neurosci 8:413-426. CrossRef Medline

Lau LF, Huganir RL (1995) Differential tyrosine phosphorylation of N-methyl-D-aspartate receptor subunits. J Biol Chem 270:20036-20041. CrossRef Medline

Lavezzari G, McCallum J, Lee R, Roche KW (2003) Differential binding of the AP-2 adaptor complex and PSD-95 to the C-terminus of the NMDA receptor subunit NR2B regulates surface expression. Neuropharmacology 45:729-737. CrossRef Medline

Lavezzari G, McCallum J, Dewey CM, Roche KW (2004) Subunit-specific regulation of NMDA receptor endocytosis. J Neurosci 24:6383-6391. CrossRef Medline

Lu YM, Roder JC, Davidow J, Salter MW (1998) Src activation in the induction of long-term potentiation in CA1 hippocampal neurons. Science 279:1363-1367. CrossRef Medline

Macdonald DS, Weerapura M, Beazely MA, Martin L, Czerwinski W, Roder JC, Orser BA, MacDonald JF (2005) Modulation of NMDA receptors by pituitary adenylate cyclase activating peptide in $\mathrm{CA} 1$ neurons requires $\mathrm{G}$ alpha $\mathrm{q}$, protein kinase C, and activation of Src. J Neurosci 25:11374-11384. CrossRef Medline

McMahon HT, Boucrot E (2011) Molecular mechanism and physiological functions of clathrin-mediated endocytosis. Nat Rev Mol Cell Biol 12: 517-533. CrossRef Medline

Motley A, Bright NA, Seaman MN, Robinson MS (2003) Clathrin-mediated endocytosis in AP-2-depleted cells. J Cell Biol 162:909-918. CrossRef Medline

Nakazawa T, Komai S, Tezuka T, Hisatsune C, Umemori H, Semba K, Mishina M, Manabe T, Yamamoto T (2001) Characterization of Fynmediated tyrosine phosphorylation sites on GluR epsilon 2 (NR2B) subunit of the N-methyl-D-aspartate receptor. J Biol Chem 276:693-699. Medline

Nakazawa T, Komai S, Watabe AM, Kiyama Y, Fukaya M, Arima-Yoshida F, Horai R, Sudo K, Ebine K, Delawary M, Goto J, Umemori H, Tezuka T, Iwakura Y, Watanabe M, Yamamoto T, Manabe T (2006) NR2B tyrosine phosphorylation modulates fear learning as well as amygdaloid synaptic plasticity. EMBO J 25:2867-2877. CrossRef Medline

Nong Y, Huang YQ, Ju W, Kalia LV, Ahmadian G, Wang YT, Salter MW (2003) Glycine binding primes NMDA receptor internalization. Nature 422:302-307. CrossRef Medline

Ohno H, Stewart J, Fournier MC, Bosshart H, Rhee I, Miyatake S, Saito T, Gallusser A, Kirchhausen T, Bonifacino JS (1995) Interaction of tyrosine-based sorting signals with clathrin-associated proteins. Science 269:1872-1875. CrossRef Medline

Ohno H, Fournier MC, Poy G, Bonifacino JS (1996) Structural determinants of interaction of tyrosine-based sorting signals with the adaptor medium chains. J Biol Chem 271:29009-29015. CrossRef Medline
Pérez-Otaño I, Ehlers MD (2005) Homeostatic plasticity and NMDA receptor trafficking. Trends Neurosci 28:229-238. CrossRef Medline

Pérez-Otaño I, Schulteis CT, Contractor A, Lipton SA, Trimmer JS, Sucher NJ, Heinemann SF (2001) Assembly with the NR1 subunit is required for surface expression of NR3A-containing NMDA receptors. J Neurosci 21:1228-1237. Medline

Pérez-Otaño I, Luján R, Tavalin SJ, Plomann M, Modregger J, Liu XB, Jones EG, Heinemann SF, Lo DC, Ehlers MD (2006) Endocytosis and synaptic removal of NR3A-containing NMDA receptors by PACSIN1/syndapin1. Nat Neurosci 9:611-621. CrossRef Medline

Prybylowski K, Chang K, Sans N, Kan L, Vicini S, Wenthold RJ (2005) The synaptic localization of NR2B-containing NMDA receptors is controlled by interactions with PDZ proteins and AP-2. Neuron 47:845-857. CrossRef Medline

Roberts AC, Díez-García J, Rodriguiz RM, López IP, Luján R, MartínezTurrillas R, Pic ó E, Henson MA, Bernardo DR, Jarrett TM, Clendeninn DJ, López-Mascaraque L, Feng G, Lo DC, Wesseling JF, Wetsel WC, Philpot BD, Pérez-Otaño I (2009) Downregulation of NR3A-containing NMDARs is required for synapse maturation and memory consolidation. Neuron 63:342-356. CrossRef Medline

Roche KW, Standley S, McCallum J, Dune Ly C, Ehlers MD, Wenthold RJ (2001) Molecular determinants of NMDA receptor internalization. Nat Neurosci 4:794-802. CrossRef Medline

Salter MW, Kalia LV (2004) Src kinases: a hub for NMDA receptor regulation. Nat Rev Neurosci 5:317-328. CrossRef Medline

Sanz-Clemente A, Matta JA, Isaac JT, Roche KW (2010) Casein kinase 2 regulates the NR2 subunit composition of synaptic NMDA receptors. Neuron 67:984-996. CrossRef Medline

Sasaki YF, Rothe T, Premkumar LS, Das S, Cui J, Talantova MV, Wong HK, Gong X, Chan SF, Zhang D, Nakanishi N, Sucher NJ, Lipton SA (2002) Characterization and comparison of the NR3A subunit of the NMDA receptor in recombinant systems and primary cortical neurons. J Neurophysiol 87:2052-2063. Medline

Scott DB, Michailidis I, Mu Y, Logothetis D, Ehlers MD (2004) Endocytosis and degradative sorting of NMDA receptors by conserved membraneproximal signals. J Neurosci 24:7096-7109. CrossRef Medline

Snyder EM, Philpot BD, Huber KM, Dong X, Fallon JR, Bear MF (2001) Internalization of ionotropic glutamate receptors in response to mGluR activation. Nat Neurosci 4:1079-1085. CrossRef Medline

Taniguchi S, Nakazawa T, Tanimura A, Kiyama Y, Tezuka T, Watabe AM, Katayama N, Yokoyama K, Inoue T, Izumi-Nakaseko H, Kakuta S, Sudo K, Iwakura Y, Umemori H, Inoue T, Murphy NP, Hashimoto K, Kano M, Manabe T, Yamamoto T (2009) Involvement of NMDAR2A tyrosine phosphorylation in depression-related behaviour. EMBO J 28:3717-3729. CrossRef Medline

Tong G, Takahashi H, Tu S, Shin Y, Talantova M, Zago W, Xia P, Nie Z, Goetz T, Zhang D, Lipton SA, Nakanishi N (2008) Modulation of NMDA receptor properties and synaptic transmission by the NR3A subunit in mouse hippocampal and cerebrocortical neurons. J Neurophysiol 99: 122-132. Medline

Trepanier CH, Jackson MF, MacDonald JF (2012) Regulation of NMDA receptors by the tyrosine kinase Fyn. FEBS J 279:12-19. CrossRef Medline

Vissel B, Krupp JJ, Heinemann SF, Westbrook GL (2001) A use-dependent tyrosine dephosphorylation of NMDA receptors is independent of ion flux. Nat Neurosci 4:587-596. CrossRef Medline

Wong HK, Liu XB, Matos MF, Chan SF, Pérez-Otaño I, Boysen M, Cui J, Nakanishi N, Trimmer JS, Jones EG, Lipton SA, Sucher NJ (2002) Temporal and regional expression of NMDA receptor subunit NR3A in the mammalian brain. J Comp Neurol 450:303-317. CrossRef Medline

Yang K, Trepanier C, Sidhu B, Xie YF, Li H, Lei G, Salter MW, Orser BA, Nakazawa T, Yamamoto T, Jackson MF, Macdonald JF (2012) Metaplasticity gated through differential regulation of GluN2A versus GluN2B receptors by Src family kinases. EMBO J 31:805-816. Medline

Zhang S, Edelmann L, Liu J, Crandall JE, Morabito MA (2008) Cdk5 regulates the phosphorylation of tyrosine $1472 \mathrm{NR} 2 \mathrm{~B}$ and the surface expression of NMDA receptors. J Neurosci 28:415-424. CrossRef Medline 